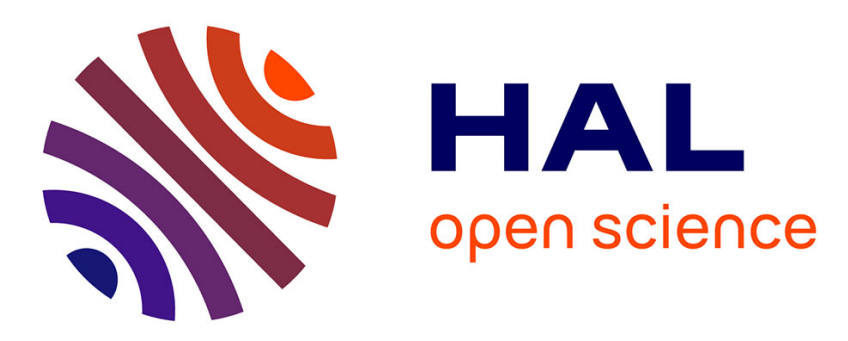

\title{
Validation of soil moisture and ocean salinity (SMOS). Soil moisture over watershed networks in the U.S.
}

\author{
T.J. Jackson, R. Bindlish, M.H. Cosh, T. Zhao, P.J. Starks, D.D. Bosch, M.
} Seyfried, M.S. Moran, D. C. Goodrich, Yann H. Kerr, et al.

\section{- To cite this version:}

T.J. Jackson, R. Bindlish, M.H. Cosh, T. Zhao, P.J. Starks, et al.. Validation of soil moisture and ocean salinity (SMOS). Soil moisture over watershed networks in the U.S.. IEEE Transactions on Geoscience and Remote Sensing, 2012, 50 (5), pp.1530-1543. 10.1109/TGRS.2011.2168533 . ird-00700841

\section{HAL Id: ird-00700841 \\ https://hal.ird.fr/ird-00700841}

Submitted on 24 May 2012

HAL is a multi-disciplinary open access archive for the deposit and dissemination of scientific research documents, whether they are published or not. The documents may come from teaching and research institutions in France or abroad, or from public or private research centers.
L'archive ouverte pluridisciplinaire HAL, est destinée au dépôt et à la diffusion de documents scientifiques de niveau recherche, publiés ou non, émanant des établissements d'enseignement et de recherche français ou étrangers, des laboratoires publics ou privés. 


\section{Validation of Soil Moisture and Ocean Salinity (SMOS) Soil Moisture over Watershed Networks in the U.S.}

Thomas J. Jackson ${ }^{\mathrm{a}}$, Rajat Bindlish ${ }^{\mathrm{a}}$, Michael Cosh ${ }^{\mathrm{a}}$, Tianjie Zhao ${ }^{\mathrm{a}}$, Patrick J. Starks ${ }^{\mathrm{b}}$, David D. Bosch ${ }^{c}$, Mark Seyfried ${ }^{d}$, M. Susan Moran ${ }^{e}$, David Goodrich ${ }^{e}$, Yann Kerr ${ }^{f}$, Delphine Leroux

a USDA ARS Hydrology and Remote Sensing Laboratory, 104 Bldg. 007 BARC-West, Beltsville, MD 20705, Tom.Jackson@ars.usda.gov

b USDA ARS Grazinglands Research Lab, El Reno, OK 73036

c USDA ARS Southeast Watershed Research Center, Tifton, GA 31793

d USDA ARS Northwest Watershed Research Center, Boise, ID, 83712

e USDA ARS Southwest Watershed Research Center, Tucson, AZ 85719

f Centre d'Etudes Spatiales de la BIOsphère, Toulouse, France 
Abstract- Estimation of soil moisture at large scale has been performed using several satellitebased passive microwave sensors and a variety of retrieval methods over the past two decades. The most recent source of soil moisture is the European Space Agency Soil Moisture and Ocean Salinity (SMOS) mission. A thorough validation must be conducted to insure product quality that will in turn support the widespread utilization of the data. This is especially important since SMOS utilizes a new sensor technology and is the first passive L-band system in routine operation. In this paper, we contribute to the validation of SMOS using a set of four in situ soil moisture networks located in the U.S. These ground-based observations are combined with retrievals based upon another satellite sensor, the Advanced Microwave Scanning Radiometer (AMSR-E). The watershed sites are highly reliable and address scaling with replicate sampling. Results of the validation analysis indicate that the SMOS soil moisture estimates are approaching the level of performance anticipated, based on comparisons with the in situ data and AMSR-E retrievals. The overall root mean square error of the SMOS soil moisture estimates is 0.043 $\mathrm{m}^{3} / \mathrm{m}^{3}$ for the watershed networks (ascending). There are bias issues at some sites that need to be addressed as well as some outlier responses. Additional statistical metrics were also considered. Analyses indicated that active or recent rainfall can contribute to interpretation problems when assessing algorithm performance, which is related to the contributing depth of the satellite sensor. Using a precipitation flag can improve performance. An investigation of the vegetation optical depth (tau) retrievals provided by the SMOS algorithm indicated that, for the watershed sites, these are not a reliable source of information on the vegetation canopy. The SMOS algorithms will continue to be refined as feedback from validation is evaluated and it is expected that the SMOS estimates will improve.

Index Terms: SMOS, AMSR-E, soil moisture, validation, and passive microwave 


\section{INTRODUCTION}

The European Space Agency (ESA) Soil Moisture and Ocean Salinity (SMOS) [1, 2] satellite utilizes technology and algorithm approaches for soil moisture retrieval that have not been employed on satellite platforms in the past. It is also the first satellite to use L-band for routine measurements (a very limited effort using a sensor on Skylab is the only precedent [3]). Validation is important for any satellite-based remote sensing product and, it is particularly significant considering the unique features of the SMOS mission. The SMOS retrieval algorithms were developed using a combination of theoretical knowledge and tower observations, which must be validated for the low resolution sensor. A variety of methodologies can be used for validation purposes that include ground-based, satellite estimates, and model products. Here we focus on ground-based observations supported by satellite estimates.

Validation has always been challenging for passive microwave remote sensing of soil moisture using ground-based observations because of the disparity in spatial support of the measurements provided by the satellite and in situ sensors. Ground-based measurements of soil moisture are made at localized points, typically $0.0025 \mathrm{~m}^{2}$, whereas satellite sensors provide an integrated area value for a much larger spatial extent, $\sim 1200 \mathrm{~km}^{2}$ for SMOS. Spatial variations in soil moisture that must be considered within these footprints occur at a variety of scales including the point scale (soil properties), over geographic units (land cover, soils, and topography), and as the result of rainfall events and climate. There are several approaches that can be used to estimate the ground-based soil moisture from point observations over the satellite footprint that include temporal stability analysis and variations of spatial sampling, both of which are utilized here $[4,5]$. 
Another formidable challenge to validation is providing continuous long term observations, which will provide a range of soil moisture conditions and seasonal patterns. In most cases, this is accomplished using in situ instrumentation, often integrated into a meteorological network. These are typically sparse and may provide only a single observation in a satellite footprint. In addition, a robust validation should include a wide range of vegetation, soil, and climate conditions if the results are to be used globally. The analysis presented in this paper is only one component of the overall SMOS validation [6]. Other contributions to this effort include [7, 8].

The approach we have developed for validating satellite-based soil moisture products is to compare the retrievals to verified estimates derived from intensive ground-based observing networks. This is founded on a set of four watershed scale in situ soil moisture networks in the U.S. These provide multiple point samples within domains that approximate a SMOS footprint for watersheds in diverse climate/vegetations regions.

The in situ networks were established in 2002 to support validation of the Advanced Microwave Scanning Radiometers (AMSR) on the ADEOS-2 and Aqua satellites [9, 10]. The reliability and accuracy of these networks have been established through extensive studies [11]. Data from the networks has been used in several related investigations [12-14]. These investigations have resulted in a good understanding of the accuracy of the various AMSR-E products that are available. In this study we will use this experience (eight years) and current AMSR-E products to assess the SMOS products. As we will describe, the two products are not expected to be the same; however, we expect that SMOS should be moving to the same level of performance at these sites that AMSR-E provides.

Data from the watershed networks and the AMSR-E products will be compared to the SMOS soil moisture products to assess the performance of the SMOS retrieval approach. 
Analysis will cover a full annual cycle. The quality of the in situ and AMSR-E data being used and the range of conditions available from these sites should be a significant contribution to the overall assessment of the SMOS mission.

It is important to note that the SMOS algorithm is evolving. As knowledge is gained from validation studies such as the one presented here, the parameters and algorithm structure are reevaluated. Exploiting this feedback is one of the reasons why validation studies are conducted. Therefore, we expect that the SMOS products will continue to improve. The current study uses the data available at the time of our analyses, which represents several incremental improvements since launch. All data were reprocessed by Centre d'Etudes Spatiales de la BIOsphère using the most recent version of the algorithm (v.400). The re-processing of the full data set by ESA is planned for the future.

\section{METHODOLOGY AND APPROACH}

A robust soil moisture validation requires high quality estimates over a wide range of cover conditions for varied climate and geographic domains. SMOS will rely on the contributions from many investigators to achieve this objective [6]. For this study we will utilize two validation resources; a set of densely sampled in situ sites and validated soil moisture products from AMSR-E. Analyses will build on our previous studies with AMSR-E [11]. Each soil moisture data set will be compared to SMOS retrievals for the period of January 2010-December 2010. A brief description of the validation resources is provided in the following sections. 


\section{A. Dense Watershed Networks}

The dense watershed networks are located at experimental watersheds operated by the USDA Agricultural Research Service; Walnut Gulch (WG), Arizona; Little Washita (LW), Oklahoma Little River (LR), Georgia; and Reynolds Creek (RC), Idaho. Soil moisture measurements taken on an hourly basis at a depth of $5 \mathrm{~cm}$ have been made at these validation sites on a continuous basis since 2002. For comparison to satellites, the nearest hourly instantaneous measurement is used. Each network is located in a different climatic region of the U.S., and each provides estimates of the average soil moisture over an area approximately the size a SMOS footprint. Soils in WG and LR are generally sandy loam, whereas LW and RC have more diverse soil textures ranging from loam to clay to sand. Supporting studies to establish the calibration and scaling of these networks have been conducted in previous field experiments [15-17]. It was determined during these previous studies that the in situ networks accurately represent the soil moisture across that domain with high accuracy $\left(<0.01 \mathrm{~m}^{3} / \mathrm{m}^{3}\right)$ when compared to a thermogravimetrically collected soil moisture from $0-5 \mathrm{~cm}$. The network average is a weighted average based on the Thiessen polygon method with standard deviations generally between 0.05 and 0.10 $\mathrm{m}^{3} / \mathrm{m}^{3}$. Only the stations which consistently provided data are used in this calculation. The in situ observations represent the watershed average. All the SMOS footprints within the watershed were averaged. A simple drop-in-bucket type of approach was used for the SMOS footprints. A single SMOS footprint may cover only part of the watershed. Moreover, single point/footprint observations are likely to have higher variability and noise. Similar approaches have been used in earlier studies. Table I summarizes some key features of the sites. Additional details can be 
found in [11]. These watersheds are characteristic of the surrounding domains, and were scaled to an approximately $50 \mathrm{~km}$ scale in [11] with success.

\section{B. AMSR-E}

A recent study [11] utilized the watershed networks with AMSR-E data to validate four alternative soil moisture algorithms over a 7-year period. Two results from that study are relevant to SMOS validation. First, the comparison of four algorithms with the in situ data revealed quite different behavior (bias, range, and accuracy). Most algorithms could meet accuracy requirements with some modification (The target accuracy for NASA (http://nsidc.org/data/amsr_validation/pdfs/Version_3_SDV_Plan.pdf) and the Japanese Aerospace Exploration Agency [9] was $0.06 \mathrm{~m}^{3} / \mathrm{m}^{3}$ ). Based upon the statistics and sites studied, the Single Channel Algorithm (SCA) [18] was found to perform as well as or better than the alternatives tested and will be used here for comparisons with SMOS. Table II summarizes the SCA statistics over the 7-year period, which will be referred to as the long term analysis.

Secondly, at this stage of SMOS validation there is some risk in reaching a conclusion with a short period of record. To illustrate this potential problem, the two primary performance metrics used for AMSR-E (Bias and Root Mean Square Error (RMSE)) were computed for an increasing period of record from the launch date. These results are shown in Figure 1 (Note that RC was not used here because only summer season data are considered reliable at that site). The plots in Figure 1 show for the watersheds with more vegetation (LR and LW) the performance in the initial months was much poorer than after approximately 6-months. This could be the result of several factors including the range of conditions observed; however, the message is clear that 
validation should proceed cautiously at the outset. It does appear that the metrics reached their long term values after 6-months.

In order to assess whether or not the available period of record for SMOS was representative in terms of soil moisture conditions and retrievals, we computed the AMSR-E SCA statistics for this same period. These are shown in Table II and are referred to as short term. A comparison of these short term values with the long term values indicates that the SCA algorithm is performing approximately the same for the two periods of record for all watersheds. For the LW and LR watersheds, the short and long term RMSE and bias are similar, which leads us to conclude that the general conditions at these sites over the first year of SMOS observations are typical of the climatology for these regions. The RMSE and bias are larger in the short term for WG and RC. The increases are not that large; however, they do indicate that there may be anomalous conditions during this short term that do not reflect the typical conditions at these watersheds. This will be taken into account in our assessment of the SMOS soil moisture retrievals.

Soil moisture retrievals from AMSR-E cannot be compared directly with SMOS products for several reasons that will be discussed below. Each satellite product must be compared to the in situ observations independently. The overall performance of the SMOS retrieval approach is then compared to that of the AMSR-E SCA for the same period of time. As discussed below, we expect that the SMOS performance should be better than the AMSR-E SCA results.

SMOS and Aqua (AMSR-E) have different orbits and as a result they may or may not pass over the watershed sites on the same day. They also have different overpass times; SMOS ascending 0600-descending 1800 and AMSR-E ascending 1330-descending 0130 local time. As a result they will be observing surface conditions at different points on the diurnal cycle. If it happened that both satellites covered a watershed on the same day, the diurnal effect would still 
be a noise factor. The observation time may also have a significant impact on the performance of the soil moisture algorithm. In general, the basic equations that these, as well as most other, algorithms are founded on assume uniform soil moisture and soil/vegetation temperature in the contributing depth. We expect these assumptions are more likely to be true in the hours near dawn when the profiles have had the most time to return to an equilibrium state from the previous day's fluxes [19]. Therefore, based upon this aspect of retrieval we might expect that the SMOS ascending 0600 soil moisture would have better performance than either of the AMSR-E SCA products.

Another difference between AMSR-E and SMOS is the frequency/wavelength. The SCA, as with most other AMSR-E soil moisture algorithms, uses the X-band channel (frequency 10.65 $\mathrm{GHz}$, wavelength $2.8 \mathrm{~cm}$ ). The longer wavelength C-band channels are not used due to widespread radio frequency interference, in particular over the U.S. SMOS provides L-band (frequency $1.41 \mathrm{GHz}$, wavelength $21.2 \mathrm{~cm}$ ). It is well known that the contributing depth [20] of the soil increases with wavelength, which results in a more stable value of soil moisture over the diurnal cycle. In addition, the effects of vegetation (in particular attenuation) are less significant at longer wavelengths [21].

Based upon the discussion of the differences between AMSR-E SCA and SMOS soil moisture retrievals above, the assumption is that the SMOS soil moisture algorithm should perform better than AMSR-E SCA. As a result, we use the AMSR-E SCA product performance as a metric, minimum level, for the SMOS product.

\section{RESULTS AND DISCUSSION}


The SMOS summary statistics for each watershed are shown in Table III. This table also includes the equivalent AMSR-E SCA results. These results have been matched up nominally in time for the two periods of day (early morning and afternoon). The overall results support the following statements:

- The SMOS RMSE is equal to or better than the AMSR-E SCA values, with the exception of LR.

- The overall SMOS RMSE values are $0.043 \mathrm{~m}^{3} / \mathrm{m}^{3}$ (ascending) and $0.047 \mathrm{~m}^{3} / \mathrm{m}^{3}$ (descending), which are very close to meeting the mission target of $0.04 \mathrm{~m}^{3} / \mathrm{m}^{3}$. These compare to the AMSR-E SCA values of $0.044 \mathrm{~m}^{3} / \mathrm{m}^{3}$ (descending) and $0.038 \mathrm{~m}^{3} / \mathrm{m}^{3}$ (ascending) respectively.

- The RMSE values do not appear to be impacted by the time of day (morning or afternoon) values (with the exception of LR descending).

- Bias values must be carefully interpreted, in some cases they are informative on algorithm performance (i.e. LR) and in others they are not (i.e. WG).

- With the exception of RC, which has a short season and low soil moisture, the correlation of the SMOS and in situ soil moisture is very good and in general better than observed for AMSR-E.

In the following sections we will analyze the results on an individual watershed basis. For each watershed we examined the plots of observed versus estimated soil moisture (Figure 2) and temporal plots of these and other variables (Figures 3 and 4). The additional variables included temperature, precipitation, and vegetation. 


\section{A. Watershed Results}

Walnut Gulch, Arizona: The watershed has a semi-arid climate. The precipitation varies significantly with two-thirds of the annual precipitation occurring in the form of high intensity convective thunderstorms with limited areal extent. Sparse desert shrubs and grass are the primary vegetation. The soil moisture exhibits a small range, due to the well drained sandy soils and limited rainfall in this area. Figure 2a shows the comparison between in situ and retrieved soil moisture. The statistical comparison (Table III) indicated that there was good agreement between the watershed observations and SMOS estimates with near zero bias. For WG, both the SMOS and AMSR-E SCA soil moisture products exceed the mission target accuracy presented earlier.

A closer examination of Figure 2a revealed that unlike the AMSR-E SCA, SMOS produces some large overestimates (both ascending and descending) and that the near zero bias may be misleading in terms of performance. Without these points, there would likely be a small underestimation bias and the overall pattern of in situ versus estimated would be very similar to the AMSR-E SCA. Since these points appear to be somewhat anomalous, we investigated possible causes for overestimation by SMOS and focused on the points in Figure 2a that were furthest from the equal values line.

Radio frequency interference was eliminated as a reason because there was no apparent problem in this region of the U.S. We examined the temporal plots of observed and estimated soil moisture and other variables; temperature, precipitation, and vegetation (only the precipitation and vegetation plots are shown in Figures 3 and 4, respectively). 
Temperature comparisons included the $5 \mathrm{~cm}$ in situ from the in situ network and the European Centre for Medium-Range Weather Forecasts (ECMWF) 0-7 cm soil temperature that is used by SMOS in the soil moisture retrieval algorithm (ver. 400). The two temperature products matched up very well for WG for the morning overpass times (as well as for all the other watersheds). Errors were a bit larger for the evening. As an example, the RMSE for the ECMWF product was $2.3^{\circ} \mathrm{C}$ with a bias of $1.8^{\circ} \mathrm{C}$. There was no apparent relationship between days with larger soil moisture errors and temperature. Note that an overestimation bias for temperature could lead to overestimation of soil moisture; however, the magnitude we observed here was very small and as a result we do not believe that temperature error plays a significant role in the soil moisture errors. This same observation was true for all the watersheds and will not be discussed any further.

Another potential source of error in retrieval may be associated with the use of ECMWF soil moisture as the initial estimate in the iterative solution procedure used by SMOS. The ECMWF soil moisture products tend to overestimate soil moisture. It is possible that starting the iteration with too high a soil moisture value might potentially bias the retrieval. However, in tests using the SMOS algorithm and initial estimates of 0 or $0.6 \mathrm{~m}^{3} / \mathrm{m}^{3}$, the same results were obtained. Using ECMWF soil moisture just saves some computation time by reducing the number of iterations and does not contribute to the retrieval error.

As noted above, precipitation in the WG region can be very intense and exhibit high spatial variability. Therefore, it is possible that the in situ network might not capture this variability, which is spatially integrated by the radiometer. For WG, as well as the other watersheds, we examined temporal plots of antecedent precipitation, as measured by rain gauges within the watershed, along with the in situ and SMOS estimated soil moisture (Figure 3). Overestimation 
of soil moisture appears to be correlated with antecedent or possibly ongoing precipitation. The reason why there might be such a relationship is that the SMOS and the in situ measurements depths are very likely to be different during and shortly after a rain event. The depth of soil that contributes to the radiometer observation becomes shallow when the near surface is wet. This may occur during and shortly after a precipitation event. After some elapsed time the soil moisture profile will become more uniform. The in situ observations are centered at $5 \mathrm{~cm}$ and include a surrounding volume. Thus, it is likely the SMOS estimate of soil moisture will be higher than the in situ when it is raining. This is not actually an error in the soil moisture algorithm, it is an error in the operational assumption we make; that the satellite sensor measures a certain depth on average. This can't be corrected; however, it may be possible to flag such conditions. We examined this by using three different precipitation flags; the ECMWF forecast rainfall, rain gauge data for a period of $+/-0.5$ hours of the over pass (active precipitation), and rain gauge data for the 6-hour antecedent period. Using the occurrence of rainfall as detected by these flags, we filtered these retrievals from the statistical analyses of RMSE and bias. The results are summarized in Table IV. Comparing these filtered data sets to the original for WG we found a reduction in the RMSE (for both ascending and descending) when using any of the flags. We also examined long antecedent intervals, not presented here, and found the there was no further improvement in the RMSE for WG, or any of the other watersheds. Changes in the bias were very small. It was observed that the improvements offered by using either the ECMWF or active precipitation flag were larger for the evening overpasses (descending). This is attributed to the typically late afternoon, high intensity, and short duration rainfall in this region. These same factors may explain why the longer duration antecedent flag improves the morning (ascending) retrievals. It should be noted that the changes in RMSE for the other watersheds were minor. 
Overestimation following rainfall events is not evident in the AMSR-E SCA data shown in Figure 2a. The explanation for this may lie in the quality and implementation of rainfall flags of the SMOS and AMSR-E SCA retrieval algorithms. For AMSR-E SCA a detection algorithm is used that employs the higher frequency channels available, which provides information on current conditions. SMOS retrievals do not directly use the ECMWF precipitation to flag the estimated soil moisture. The ECMWF precipitation flag is used only in the case of heavy convective rainfall as an indicator of possible high canopy interception. The algorithm uses tau retrievals in subsequent orbits if there aren’t a sufficient number of incidence angles available. The tau retrieval from the previous overpass is also used as a first guess in the iteration process. If there is a high canopy interception flag then that tau is not used in the future retrievals.

It is possible that the number and intensity of precipitation events in 2010 was higher than normal. As noted earlier, the AMSR-E short term statistics indicated that the errors were higher than usual in 2010. From this we can infer that the performance statistics for SMOS in WG will likely improve as the period of record increases. Another factor we investigated was vegetation. Normalized Difference Vegetation Index (NDVI) climatology was derived using 10 years (2000-2010) of MODIS (Terra) observations. Individual MODIS observations were screened for precipitation, cloud cover and snow. Quality control flags were used to screen out the bad data values. The quality controlled data was averaged for every 10 -day period to derive a yearly climatology. The NDVI was converted to vegetation water content (VWC). The relationship between NDVI and VWC was established by comparing the ground based spectral observations with the in situ vegetation water content observations. In situ vegetation water content was measured by destructive sampling. The following studies provide detailed descriptions of the methodology and the results based on several field campaigns [22-24]. 
The VWC data were used to analyze the vegetation optical depth or tau values [21] retrieved by the SMOS algorithm. Figure 4a shows the plots for the ascending overpass (similar behavior was observed for the descending passes, summary values for both passes are included in Table VI). As noted previously, there is very little vegetation in WG. The changes that occur during the year are associated with rainfall events, which are more common during the late summer period. The VWC curve in Figure 4a reflects these phenomena.

In Figure 4a, tau exhibits large day to day variability that does not appear to be associated with changes in the vegetation. In addition, these deviations do not seem to be directly related to differences between the in situ and SMOS soil moisture since they occur during periods with both nominal as well as large errors and show no seasonal pattern. As described in [21], tau can be approximated by the product of VWC and a vegetation canopy parameter b. Using the guidelines for estimating b in [21] the resulting values of vegetation water content for WG would be much higher than have been observed in this area [22]. This result raises concerns on what SMOS tau parameter is representing.

The variability of tau from day to day, the lack of a seasonal response, and the level of tau for this particular watershed indicated to us that these estimates may be dependent on other factors beyond the vegetation. These could include the quality of the brightness temperatures.

There are some problems with the SMOS FOV that impact brightness temperature estimates at certain angles on some days. The fact that SMOS uses 2D aperture synthesis results in snapshot images that include areas that are either in the alias free or extended alias free field of view (FOV). The extended zones have some sky present in the field of view. Only the center part of the snapshot contains the alias free FOV. The edges of the orbit swath include observations from the extended alias free FOV. Therefore, some of the variation in tau we observed in Figure 
4a may be related to brightness temperature variations associated with this issue. Additional details on aliasing can be found in [25-28].

Little Washita, Oklahoma: The watershed has a sub-humid climate. Soils include a wide range of textures with large regions of both coarse and fine textures. Land use is dominated by rangeland and pasture with significant areas of winter wheat. The statistical comparison of in situ versus retrieved soil moisture (Table III) indicated that there was good agreement; the SMOS RMSE is a bit larger than the target accuracy but better than the AMSR-E SCA for both overpass times. Bias for SMOS was near zero; whereas the AMSR-E SCA had a moderate underestimation error.

Figure $2 \mathrm{~b}$ shows in situ versus retrieved soil moisture for SMOS and the AMSR-E SCA. The overall patterns are similar to each other but there were more overestimates for SMOS. Based upon these results, we believe that the SMOS algorithm is performing as expected for LW. It should be noted that the range of soil moisture for LW was one of the largest we observed for the watershed sites.

As in the case of WG, we examined temporal plots of antecedent precipitation with the in situ and SMOS estimated soil moisture for LW (Figure 3b, ascending) and found some evidence of the pattern we observed for WG. However, when the RMSE values for the two precipitation flags were computed (Table IV) the impact of removing these events was smaller, a decrease from 0.042 to $0.036 \mathrm{~m}^{3} / \mathrm{m}^{3}$. The active and 6-hour flags produced similar results and bias was small for all cases. The use of precipitation improved the AMSR-E SCA by only a small amount.

The tau and VWC values for LW are presented as a temporal plot in Figure 4b and summarized in Table VI. The typical vegetation phenology for this region is clearly illustrated in 
the VWC. Winter wheat greens up in April and is harvested by early June. At the same time that the wheat is senescing, grasses and summer crops begin to contribute to the average VWC, which results in more or less constant VWC through summer. As observed for WG; tau does not exhibit any clear seasonal pattern and, it has high day to day variability, and the level of tau appears to be higher than expected.

Little River, Georgia: This watershed has a sub-humid climate with long hot and humid summers and short mild winters. Sandy loam soils dominate. The major land cover in the watershed is cropland (consisting mostly of summer crops such as peanuts and cotton), forest, and pasture. The statistical comparisons in Table III indicate a higher RMSE and an overestimation bias for SMOS ascending than was found for the other watersheds. This compares to good performance for the AMSR-E SCA algorithm, which also had an overestimation bias. Unlike the results for the other watersheds, there was a large increase in RMSE and bias for the descending pass retrievals.

Figure 2c further illustrates the comments above. It shows that the overall scatter of the in situ versus retrieved soil moisture is similar for SMOS and the AMSR-E SCA with one exception; SMOS has a large number of overestimates for the descending pass. We have previously suggested that one cause of these overestimation errors might be antecedent precipitation. Afternoon (evening) overpasses for SMOS (descending) occur during the time of day when convective rainfall is more likely to occur.

Figures 3c shows the LR temporal plots of antecedent precipitation with the in situ and SMOS estimated soil moisture, ascending. The RMSE and bias values for the two flags are summarized in Table IV. For the ascending passes there is very little impact of using the flags, as 
indicated by the RMSE. However, there was a change in the bias from overestimation to underestimation. For the descending passes there is a small improvement $\left(0.072\right.$ to $0.064 \mathrm{~m}^{3} / \mathrm{m}^{3}$ when using the 6-hour flag). These results suggest that some of the larger than expected error for LR may be associated with precipitation.

The LR tau values (Figure 4c) exhibit the same day to day variability we observed for the other watersheds. They also do not reflect the expected seasonal pattern we would expect for this region based on VWC.

Reynolds Creek, Idaho: The land cover in the RC watershed is predominantly rangeland. About $75 \%$ of the annual precipitation in the higher elevations is snow whereas less than $25 \%$ is snow at lower elevations. Soils range from steep rocky, shallow soils in the mid elevations to rock free saline soils in the valley to slightly acid soils in the upper elevations. In order to eliminate the effect of snow on SMOS retrievals, only data from July-September was used in the analysis (this is the same approach used with the AMSR-E SCA). In reviewing Table III, we found for RC that the SMOS retrievals performed better than the AMSR-E SCA for the ascending passes and exceeded the target accuracy. There was an underestimation bias for both the ascending and descending data and that the descending value exceeds the target accuracy. Figure $2 \mathrm{~d}$ shows that the available data covers only a limited range of soil moisture conditions.

With regard to precipitation effects, there were few data points and even fewer precipitation events during the study period (Figure 3d). The precipitation flag results in Tables IV and V indicated that the use of the flags did not have much impact on RMSE or bias. These should be interpreted with care. 
The behavior of the RC tau values was different than what we observed for the other watersheds. (Figure 4d). The day to day variations are present; however, there may be a pattern. There appears to be a cycle approximately every two weeks in which there is a rapid increase followed by a slower decay with a secondary increase. In addition the increases in tau seem to correspond to increases in SMOS soil moisture (that is not explained by the in situ soil moisture). This result suggests a problem related to the algorithm and may be associated with the orbit pattern and position of the site within the snapshot.

The general underestimation of soil moisture at this site (Figure 3d) may be more apparent due to the overall drier conditions that typically occur. This could be associated with the choice of the soil dielectric mixing model, which might be re-evaluated in the future.

\section{B. Discussion of Precipitation Flags}

It is well known from theory [29] that both the amount of soil moisture and its distribution within the contributing depth of the soil can affect the resulting brightness temperature. With a complete radiative transfer model and a detailed description of the soil moisture (dielectric constant) profile it is possible to simulate brightness temperature. However, it is not possible to retrieve the near surface soil moisture profile from observations of brightness temperature, especially when the near surface layer is wet. As a result, most retrieval algorithms incorporate the assumption of uniform soil moisture over a fixed depth ( $5 \mathrm{~cm}$ for L-band), which facilitates the use of the Fresnel equations in retrieval algorithms.

The in situ sensors are installed at a fixed depth and in the case of the watershed networks; supplemental investigations were conducted to establish the relationship of these measurements 
and the soil moisture in the $0-5 \mathrm{~cm}$ layer. As a result, validation compares this verified average value to the radiometer estimate under the assumption that both sensors are responding to soil moisture within the same soil layer.

When rain occurs it wets the layer from the surface. If the rain amount is large enough, a thin saturated soil layer can result in a contributing depth that is shallower than $5 \mathrm{~cm}$. In this situation, the retrieved soil moisture may be accurate but it is representative of a different depth than the in situ validation measurement. This will result in overestimation. The occurrence of this condition is more likely when the soil is initially dry and the precipitation event is of short duration and high intensity. We might expect this to be more significant for WG than the other watersheds, which supports the results in Table IV.

Following a rainfall event, the soil moisture within the surface soil layer will equilibrate through drainage and hydraulic redistribution. The time required to reach this state depends on the antecedent conditions, intensity of precipitation, and the soil hydraulic properties.

The discussion above is meant to provide background on why SMOS soil moisture retrievals during active or after recent rainfall contribute to possible increased RMSE and overestimation bias. Questions to consider are whether these retrievals should be included in validation and how these might be identified (flagged). We feel that the validation should be conducted with and without them and both results should be presented. Based on our analyses, the ECMWF flag appears to perform about the same as those based on measured precipitation. Since this data is available to the SMOS retrieval algorithm, it is suggested that it be implemented as a flag.

\section{Discussion of Vegetation Optical Depth (Tau)}


An intriguing aspect of the SMOS observations over land is the possibility of obtaining vegetation information from the tau or optical depth values provided as part of SMOS soil moisture retrieval. Tau is related to vegetation water content and structure [18]. Vegetation water content is also related to vegetation indices such as the NDVI [22-24].

Tau is obtained by optimizing the brightness temperature observations within the algorithm approach [2]. The first guess is either derived from the previous acquisition (and then constrained using the brightness temperature observations) or from a Leaf Area Index (LAI) climatology (not constrained). It is possible that the estimate from the LAI climatology can be significantly different from the estimated values of tau. These differences may explain some of the variations in the retrieved values. In the center part of the swath a multi-parameter retrieval is done [30]. If the pixel is located closer to the edge of the orbit a smaller number of incidence angle observations will be available. In this case, the tau estimate from the previous acquisition is used in the soil moisture retrieval.

Tau typically does not vary on a daily basis. It is dependent on the vegetation phenology and follows a yearly cycle based on the vegetation growth. Significant variations are more likely to occur over a weekly time frame. SMOS has a revisit frequency of 3 days. But, only the center portion of the orbit has a sufficient number of incidence angles for the multi-parameter retrieval. This results in an updated (retrieved) tau only every 7-10 days.

For the sites analyzed, we found that tau varied significantly on a day to day basis over the course of the year. This variability was not reflected in the soil moisture retrievals, with the exception of RC. Since we know that tau plays a significant role in attenuating the information from the soil, it is confusing that the variation in tau is not translated into variations in soil 
moisture. We can only conjecture that some other parameter in the algorithm is compensating for these changes.

None of the watershed sites had an annual pattern of tau that followed the typical seasonal pattern that we expect based upon the local climatology and VWC. We recognize that the analysis involves a limited set of conditions; however, the lack of a seasonal cycle in tau suggests that this parameter, as retrieved by the SMOS algorithm, is not a reliable indicator of VWC or biomass.

Another concern we have with tau as a vegetation indicator is the lack of its correspondence to the relative vegetation levels in the four watersheds. As shown in Table VI and discussed in the paper, the SMOS tau levels are lower than expected. It is possible the higher tau values are a result of compensation for another model parameter. One such factor is the surface roughness effect. The effective roughness parameter was assumed to be constant value of 0.1 . Surface roughness and tau have a similar effect on the surface emissivity. It is possible the residual surface roughness is compensated for by the increase in tau. The values for vegetation optical depth (tau) are significantly higher than the MODIS derived VWC for the WG and RC watersheds. These watersheds also have higher surface roughness. Based upon these facts, as the present time the tau parameter should not be used as a vegetation index.

\section{SUMMARY}

The results of our validation indicate that the SMOS soil moisture estimates are approaching the level of performance anticipated, based on comparisons with in situ data and supported by soil moisture retrievals using AMSR-E data and its associated algorithm. The watershed sites are 
highly reliable and address scaling with replicate sampling. The overall RMSE of the SMOS soil moisture estimates is $0.043 \mathrm{~m}^{3} / \mathrm{m}^{3}$ (ascending) and $0.047 \mathrm{~m}^{3} / \mathrm{m}^{3}$ (descending), for the watershed networks. These are very close to the mission target accuracy of $0.04 \mathrm{~m}^{3} / \mathrm{m}^{3}$.

Our analyses indicated that ongoing and recent precipitation can contribute to the error in using the in situ data to validate the SMOS retrievals. The in situ data represent average conditions in the 0-5 cm soil layer. At L-band, SMOS can also provide an estimate of this layer. However, shortly after a rain event the radiometer measurement will be dominated by the wetter near surface layer. The difference between the in situ and SMOS estimates of soil moisture in these cases is due to interpretation rather than retrieval error. It was shown that ECMWF precipitation forecast data can be used to flag these events. Applying this precipitation flag reduces the RMSE in most cases.

SMOS provides a parameter tau as part of its retrieval scheme. Tau is the nadir vegetation optical depth and is related to the vegetation water content and other biophysical variables. For the sites analyzed we found that tau varied significantly on a day to day basis, did not mimic the seasonal patterns we expected for the sites, and did not match the level of tau as estimated using other techniques. Based upon these facts, the tau parameter should not be used as a vegetation index.

The SMOS algorithms are still being modified and are in calibration/validation phase. It is expected that refinements to the SMOS algorithm will further enhance the soil moisture retrievals. 


\section{ACKNOWLEDGMENTS}

The SMOS data were provided through the ESA supported SMOS Validation and Retrieval Team program.

The U.S. Department of Agriculture (USDA) prohibits discrimination in all its programs and activities on the basis of race, color, national origin, age, disability, and where applicable, sex, marital status, familial status, parental status, religion, sexual orientation, genetic information, political beliefs, reprisal, or because all or part of an individual's income is derived from any public assistance program. (Not all prohibited bases apply to all programs.) Persons with disabilities who require alternative means for communication of program information (Braille, large print, audiotape, etc.) should contact USDA's TARGET Center at (202) 720-2600 (voice and TDD). To file a complaint of discrimination, write to USDA, Director, Office of Civil Rights, 1400 Independence Avenue, S.W., Washington, D.C. 20250-9410, or call (800) 7953272 (voice) or (202) 720-6382 (TDD). USDA is an equal opportunity provider and employer. 


\section{REFERENCES}

[1] Y. H. Kerr, P. Waldteufel, J., Wigneron, S. Delwart, F. Cabot, J. Boutin, M. Escorihuela, J. Font, N. Reul, C. Gruhier, S.E. Juglea, M.R. Drinkwater, A. Hahne, M. Ma -Neira, and S. Mecklenburg, “The SMOS mission: New tool for monitoring key elements of the global water cycle,” Proceedings of the IEEE, vol. 98, no. 5, pp. 666- 687, 2010.

[2] Y. H. Kerr, P. Waldteufel, P .Richaume, J. P. Wigneron, P. Ferrazzoli, A. Mahmoodi, A. Al Bitar, F. Cabot, C. Gruhier, S. Juglea, D. Leroux, A. Mialon, and S. Delwart, "The SMOS soil moisture retrieval algorithm,” IEEE Transactions on Geoscience and Remote Sensing, submitted this issue.

[3] J. R. Eagleman and W. C. Lin, "Remote Sensing of soil moistue by a 21-cm passive radiometer,” J. Geophys. Res., 81, pp. 3660-3666, 1976.

[4] L. Brocca, F. Melone, T. Moramarco, and R. Morbidelli, "Spatial-temporal variability of soil moisture and its estimation across scales,” Water Resources Research, vol. 46, W02516, doi:10.1029/2009WR008016, 2010.

[5] A. W. Western and G. Bloschl, “On the spatial scaling of soil moisture,” J. Hydrology., vol. 217, pp. 203-224, doi:10.1016/S0022-1694(98)00232-7. 1999.

[6] S. Delwart, C. Bouzinac, P. Wursteisen, M. Berger, M. Drinkwater, M. Martín-Neira, and Y. H. Kerr, "SMOS validation and the COSMOS campaigns,” IEEE Trans. Geosci. Remote Sens., vol. 46, no. 3, pp. 695-704, 2008.

[7] A. Al Bitar, D. Leroux, Y. H. Kerr , O. Merlin, P. Richaume, A. Sahoo, and E. Wood, "Evaluation of SMOS soil moisture products over continental US using the 
SCAN/SNOTEL network, IEEE Transactions on Geoscience and Remote Sensing, submitted this issue.

[8] S. Peischl, J. P. Walker, C. Rüdiger, N. Ye, Y. H. Kerr, and E. Kim, "The AACES field experiments: SMOS calibration and validation across the Murrumbidgee River Catchment,” IEEE Transactions on Geoscience and Remote Sensing, submitted this issue.

[9] A. Shibata, K. Imaoka, and T. Koike, "AMSR/AMSR-E level 2 and 3 algorithm developments and data validation plans of NASDA,” IEEE Trans. Geosci. Rem. Sens., vol. 41, pp. 195-203, 2003.

[10] E. G. Njoku, T. J. Jackson, V. Lakshmi, T. K. Chan, and S. V. Nghiem, "Soil moisture retrieval from AMSR-E,” IEEE Trans. Geosci. Rem. Sens.,, vol. 41, no. 2, pp. 215-229, 2003.

[11] T. J. Jackson, M. Cosh, R. Bindlish, P. Starks, D. Bosch, M. Seyfried, D. Goodrich, S. Moran, and J. Du, "Validation of Advanced Microwave Scanning Radiometer soil moisture products," IEEE Trans. Geosci. Rem. Sens., vol. 48, no. 12, pp. 4256 - 4272, 2010.

[12] Q. Liu, R. H. Reichle, R. Bindlish, M. H. Cosh, W. T. Crow, R. de Jeu, G. De Lannoy, G. J. Huffman, and T. J. Jackson,'The contributions of precipitation and soil moisture observations to the skill of soil moisture estimates in a land data assimilation system,” Journal of Hydrometeorology, in press.

[13] D. Mirrales, W. T. Crow, and M. H. Cosh, "A technique for estimating spatial sampling errors in coarse-scale soil moisture estimates derived from point-scale observations,” Journal of Hydrometeorology, vol. 11, no. 6, pp. 1423-1429, 2010. 
[14] L. Li, P. W. Gaiser, B. C. Gao, R. M. Bevilacqua, T. J. Jackson, E. G. Njoku, C., Rüdiger, J. Calvet, and R. Bindlish, "WindSat global soil moisture retrieval and validation," IEEE Trans. Geosci. Rem. Sens., vol. 48, no. 5, pp. 2224-2241, 2010.

[15] M. H. Cosh, T. J. Jackson, P. J. Starks, and G. C. Heathman, “Temporal Stability of surface soil moisture in the Little Washita and its applications in satellite soil moisture product validation,” Journal of Hydrology, vol. 323, pp. 168-177, 2006.

[16] M. H. Cosh, T. J. Jackson, M. S. Moran, and R. Bindlish, "Temporal persistence and stability of surface soil moisture in a semi-arid watershed," Remote Sensing of Environment, vol. 112, pp. 304-313, 2008.

[17] D. D. Bosch, V. Lakshmi, T. J. Jackson, M. Choi, and J. M. Jacobs, "Large scale measurements of soil moisture for validation of remotely sensed data: Georgia soil moisture experiment of 2003,” Journal of Hydrology, vol. 323, pp. 120-137, 2006.

[18] T. J. Jackson, "Measuring surface soil moisture using passive microwave remote sensing," Hydrol. Processes, vol. 7, pp.139-152, 1993.

[19] T. J. Jackson, "Profile soil moisture from surface measurements," Journal of the Irrigation and Drainage Division of the ASCE, vol. 106, no. IR2, pp. 81-92, 1980.

[20] F. T. Ulaby, R. K.Moore, and A. K. Fung, "Microwave remote sensing, active and passive, Volume III: From theory to applications,” Artech House, Dedham, MA. 1986.

[21] T. J. Jackson and T. J. Schmugge, "Vegetation effects on the microwave emission from soils,” Rem. Sens. Environ., vol. 36, pp. 203-212, 1991.

[22] M. T. Yilmaz, E. R. Hunt Jr., L. D. Goins, S. L. Ustin, V. C. Vanderbilt and T. J. Jackson, "Vegetation water content during SMEX04 from ground data and Landsat 5 Thematic Mapper imagery,” Rem. Sens. Environ, 112, pp. 350-362, 2008. 
[23] T. J. Jackson, D. M. Le Vine, A. Y. Hsu, A. Oldak, P. J. Starks, C. T. Swift, J. D. Isham, and M. Haken, "Soil moisture mapping at regional scales using microwave radiometry: the Southern Great Plains hydrology experiment,” IEEE Trans. on Geoscience and Remote Sensing, vol. 37, no. 5, pp. 2136-2151, 1999.

[24] T. Jackson, D. Chen, M. Cosh, F. Li, M. Anderson, C. Walthall, P. Doraiswamy, and E. R. Hunt, "Vegetation water content mapping using Landsat data derived normalized difference water index (NDWI) for corn and soybean,” Remote Sensing of Environment, vol. 92, pp. 475-482, 2004.

[25] E. Anterrieu, "A resolving matrix approach for synthetic aperture imaging radiometers," IEEE Trans Geosci. Remote Sens., vol. 42, pp. 1649-1656, 2004.

[26] E. Anterrieu, P. Waldteufel, and G. Caudal, "About the effects of instrument errors in interferometric radiometry," Radio Sciences, vol. 38, pp. 8044, doi: 10.1029/2002RS002750, 2003.

[27] I. Corbella, F. Torres, A. Camps, A. Colliander, M. Martín-Neira, S. Ribó, K. Rautiainen, N. Duffo, and M. Vall-llossera, "MIRAS end-to-end calibration: Application to SMOS L1 processor,” IEEE Transactions on Geoscience and Remote Sensing, vol. 43, no. 5, pp. 11261134, 2005.

[28] A. Camps, M. Vall-llossera, N. Duffo, M. Zapata, I. Corbella, F. Torres, and V. Barrena, “Sun effects in 2D aperture synthesis radiometry imaging and their cancellation," IEEE Transactions on Geoscience and Remote Sensing, Vol. 42, no. 6, pp. 1161-1167, 2004

[29] E. G. Njoku and J. A. Kong, “Theory for passive microwave remote sensing of near-surface soil moisture,” J. Geophys. Res., vol. 82, pp. 3108-3118, 1977. 
[30] J. P. Wigneron, A. Chanzy, J. C. Calvet, and N. Bruguier, “A simple algorithm to retrieve soil moisture and vegetation biomass using passive microwave measurements over crop fields,” Remote Sensing of Environment, vol. 51, pp. 331-341, 1995. 
Table I. USDA ARS watershed characteristics.

\begin{tabular}{|c|c|c|c|c|c|c|c|}
\hline Watershed & $\begin{array}{c}\text { Size } \\
\left(\mathrm{km}^{2}\right)\end{array}$ & $\begin{array}{c}\text { Soil } \\
\text { Moisture } \\
\text { Sites }\end{array}$ & Climate & $\begin{array}{c}\text { Annual } \\
\text { Rainfall } \\
(\mathrm{mm})\end{array}$ & $\begin{array}{c}\text { Common } \\
\text { Soil Types }\end{array}$ & Topography & Land Use \\
\hline $\begin{array}{c}\text { Walnut } \\
\text { Gulch, AZ }\end{array}$ & 148 & 21 & Semiarid & 320 & Sandy Loam & Rolling & Range \\
\hline $\begin{array}{c}\text { Little } \\
\text { Washita, } \\
\text { OK }\end{array}$ & 610 & 16 & $\begin{array}{c}\text { Sub } \\
\text { humid }\end{array}$ & 750 & $\begin{array}{c}\text { Silt, Loam/ } \\
\text { Sand* }\end{array}$ & Rolling & Range/wheat \\
\hline $\begin{array}{c}\text { Little } \\
\text { River, GA }\end{array}$ & 334 & 29 & Humid & 1200 & Sandy Loam & Flat & $\begin{array}{c}\text { Row } \\
\text { crop/forest }\end{array}$ \\
\hline $\begin{array}{c}\text { Reynolds } \\
\text { Creek, ID }\end{array}$ & 238 & 19 & Semiarid & 500 & $\begin{array}{c}\text { Loam/Sandy } \\
\text { Loam * }\end{array}$ & Mountainous & Range \\
\hline
\end{tabular}

*Soils are heterogeneous. 
Table II. Comparison of long term and short term SCA performance with AMSR-E. The long term analysis covers a period of June 2002-Dec 2010. The short term covers the period of the SMOS data set used in analyses, Jan. 2010-Dec. 2010.

\begin{tabular}{|c|c|c|c|c|c|}
\hline \multirow{2}{*}{ Watershed } & \multirow{2}{*}{ Period } & \multicolumn{2}{|c|}{$\begin{array}{c}\text { AMSR-E } \\
\text { Descending } 0130\end{array}$} & \multicolumn{2}{|c|}{$\begin{array}{c}\text { AMSR-E } \\
\text { Ascending } 1330\end{array}$} \\
\hline & & RMSE & Bias & RMSE & Bias \\
\hline \multirow{2}{*}{$\begin{array}{c}\text { Walnut Gulch, } \\
\text { AZ }\end{array}$} & Long Term & 0.024 & -0.011 & 0.027 & -0.016 \\
\hline & Short Term & 0.038 & -0.029 & 0.030 & -0.021 \\
\hline \multirow{2}{*}{$\begin{array}{l}\text { Little Washita, } \\
\text { OK }\end{array}$} & Long Term & 0.052 & -0.019 & 0.047 & -0.018 \\
\hline & Short Term & 0.046 & -0.029 & 0.048 & -0.035 \\
\hline \multirow{2}{*}{$\begin{array}{l}\text { Little River, } \\
\text { GA }\end{array}$} & Long Term & 0.051 & 0.035 & 0.038 & 0.018 \\
\hline & Short Term & 0.049 & 0.040 & 0.034 & 0.021 \\
\hline \multirow{2}{*}{$\begin{array}{l}\text { Reynolds } \\
\text { Creek, ID }\end{array}$} & Long Term & 0.027 & -0.014 & 0.029 & -0.017 \\
\hline & Short Term & 0.041 & -0.035 & 0.044 & -0.039 \\
\hline
\end{tabular}


Table III. Comparison of SMOS and AMSR-E SCA soil moisture algorithm performance for the watershed networks (Jan. 2010-Dec. 2010).

\begin{tabular}{|c|c|c|c|c|c|c|c|c|c|}
\hline \multirow{2}{*}{ Watershed } & \multirow{2}{*}{ Product } & \multicolumn{4}{|c|}{$\begin{array}{c}\text { SMOS Ascending } 0600 \\
\text { AMSR-E Descending } 0130 \\
\end{array}$} & \multicolumn{4}{|c|}{$\begin{array}{c}\text { SMOS Descending } 1800 \\
\text { AMSR-E Ascending } 1330 \\
\end{array}$} \\
\hline & & RMSE & Bias & $\mathrm{R}$ & $\mathrm{N}$ & RMSE & Bias & $\mathrm{R}$ & $\mathrm{N}$ \\
\hline \multirow{2}{*}{$\begin{array}{l}\text { Walnut } \\
\text { Gulch, AZ }\end{array}$} & SMOS & 0.038 & 0.003 & 0.809 & 128 & 0.034 & 0.004 & 0.762 & 145 \\
\hline & AMSR-E & 0.038 & -0.029 & 0.472 & 247 & 0.030 & -0.021 & 0.471 & 216 \\
\hline \multirow{2}{*}{$\begin{array}{c}\text { Little } \\
\text { Washita, OK }\end{array}$} & SMOS & 0.042 & 0.002 & 0.773 & 130 & 0.044 & -0.008 & 0.775 & 134 \\
\hline & AMSR-E & 0.046 & -0.029 & 0.709 & 214 & 0.048 & -0.035 & 0.790 & 244 \\
\hline \multirow{2}{*}{$\begin{array}{c}\text { Little River, } \\
\text { GA }\end{array}$} & SMOS & 0.051 & 0.026 & 0.732 & 126 & 0.072 & 0.045 & 0.643 & 92 \\
\hline & AMSR-E & 0.049 & 0.040 & 0.631 & 224 & 0.034 & 0.021 & 0.792 & 243 \\
\hline \multirow{2}{*}{$\begin{array}{l}\text { Reynolds } \\
\text { Creek, ID }\end{array}$} & SMOS & 0.039 & -0.023 & 0.152 & 51 & 0.045 & -0.016 & 0.136 & 42 \\
\hline & AMSR-E & 0.041 & -0.035 & 0.172 & 74 & 0.044 & -0.039 & 0.045 & 76 \\
\hline
\end{tabular}


Table IV. Effect of flagging and removal on SMOS soil moisture algorithm performance when there is active or recent rainfall.

\begin{tabular}{|c|c|c|c|c|c|c|c|c|c|}
\hline \multirow{2}{*}{ Watershed } & \multirow{2}{*}{ Flag } & \multicolumn{4}{|c|}{ SMOS Ascending 0600} & \multicolumn{4}{|c|}{ SMOS Descending 1800} \\
\hline & & RMSE & Bias & $\mathrm{R}$ & $\mathrm{N}$ & RMSE & Bias & $\mathrm{R}$ & $\mathrm{N}$ \\
\hline \multirow{4}{*}{$\begin{array}{l}\text { Walnut } \\
\text { Gulch, AZ }\end{array}$} & None & 0.038 & 0.003 & 0.809 & 128 & 0.034 & 0.004 & 0.762 & 145 \\
\hline & ECMWF & 0.027 & 0.007 & 0.763 & 109 & 0.019 & 0.006 & 0.847 & 106 \\
\hline & $\begin{array}{l}\text { Active } \\
\text { Rain }\end{array}$ & 0.034 & 0.001 & 0.820 & 121 & 0.021 & 0.006 & 0.808 & 111 \\
\hline & \begin{tabular}{|c|} 
6-Hour \\
Antecedent
\end{tabular} & 0.024 & 0.008 & 0.678 & 106 & 0.019 & 0.007 & 0.840 & 100 \\
\hline \multirow{4}{*}{$\begin{array}{c}\text { Little } \\
\text { Washita, OK }\end{array}$} & None & 0.042 & 0.002 & 0.773 & 130 & 0.044 & -0.008 & 0.775 & 134 \\
\hline & ECMWF & 0.033 & 0.003 & 0.805 & 94 & 0.042 & 0.011 & 0.796 & 100 \\
\hline & $\begin{array}{l}\text { Active } \\
\text { Rain }\end{array}$ & 0.036 & 0.003 & 0.785 & 121 & 0.041 & 0.012 & 0.792 & 123 \\
\hline & \begin{tabular}{|c|} 
6-Hour \\
Antecedent
\end{tabular} & 0.036 & 0.003 & 0.780 & 112 & 0.042 & 0.013 & 0.767 & 115 \\
\hline \multirow{4}{*}{$\begin{array}{l}\text { Little River, } \\
\text { GA }\end{array}$} & None & 0.051 & 0.026 & 0.732 & 126 & 0.072 & 0.045 & 0.643 & 92 \\
\hline & ECMWF & 0.054 & -0.023 & 0.644 & 98 & 0.083 & -0.059 & 0.610 & 87 \\
\hline & \begin{tabular}{|c|} 
Active \\
Rain \\
\end{tabular} & 0.049 & -0.024 & 0.694 & 112 & 0.066 & -0.038 & 0.653 & 77 \\
\hline & \begin{tabular}{|c|} 
6-Hour \\
Antecedent
\end{tabular} & 0.048 & -0.024 & 0.717 & 96 & 0.064 & -0.036 & 0.638 & 64 \\
\hline \multirow{4}{*}{$\begin{array}{l}\text { Reynolds } \\
\text { Creek, ID }\end{array}$} & None & 0.039 & -0.023 & 0.152 & 51 & 0.045 & -0.016 & 0.136 & 42 \\
\hline & ECMWF & 0.038 & 0.026 & 0.230 & 48 & 0.039 & 0.025 & 0.129 & 36 \\
\hline & $\begin{array}{l}\text { Active } \\
\text { Rain }\end{array}$ & 0.040 & 0.025 & 0.083 & 47 & 0.039 & 0.027 & 0.342 & 37 \\
\hline & \begin{tabular}{|c|} 
6-Hour \\
Antecedent
\end{tabular} & 0.039 & 0.027 & 0.145 & 46 & 0.040 & 0.027 & 0.176 & 35 \\
\hline
\end{tabular}


Table V. Flagging and removal on AMSR-E SCA soil moisture algorithm performance when there is active or recent rainfall.

\begin{tabular}{|c|c|c|c|c|c|c|c|c|c|}
\hline \multirow{2}{*}{ Watershed } & \multirow{2}{*}{ Flag } & \multicolumn{4}{|c|}{ AMSR-E Descending 0130} & \multicolumn{4}{|c|}{ AMSR-E Ascending 1330} \\
\hline & & RMSE & Bias & $\mathrm{R}$ & $\mathrm{N}$ & RMSE & Bias & $\mathrm{R}$ & $\mathrm{N}$ \\
\hline \multirow{3}{*}{$\begin{array}{c}\text { Walnut } \\
\text { Gulch, AZ }\end{array}$} & None & 0.038 & -0.029 & 0.472 & 247 & 0.030 & -0.021 & 0.471 & 216 \\
\hline & $\begin{array}{l}\text { Active } \\
\text { Rain }\end{array}$ & 0.028 & -0.020 & 0.483 & 202 & 0.035 & -0.026 & 0.388 & 205 \\
\hline & $\begin{array}{c}\text { 6-Hour } \\
\text { Antecedent }\end{array}$ & 0.025 & -0.018 & 0.364 & 170 & 0.032 & -0.024 & 0.255 & 177 \\
\hline \multirow{3}{*}{$\begin{array}{c}\text { Little } \\
\text { Washita, } \\
\text { OK }\end{array}$} & None & 0.046 & -0.029 & 0.709 & 214 & 0.048 & -0.035 & 0.790 & 244 \\
\hline & $\begin{array}{c}\text { Active } \\
\text { Rain } \\
\end{array}$ & 0.045 & -0.029 & 0.702 & 208 & 0.045 & -0.033 & 0.798 & 223 \\
\hline & \begin{tabular}{c|} 
6-Hour \\
Antecedent \\
\end{tabular} & 0.045 & -0.029 & 0.696 & 194 & 0.044 & -0.033 & 0.790 & 207 \\
\hline \multirow{3}{*}{$\begin{array}{l}\text { Little } \\
\text { River, } \\
\text { GA }\end{array}$} & None & 0.049 & 0.040 & 0.631 & 224 & 0.034 & 0.021 & 0.792 & 243 \\
\hline & $\begin{array}{c}\text { Active } \\
\text { Rain } \\
\end{array}$ & 0.048 & 0.039 & 0.609 & 208 & 0.034 & 0.023 & 0.784 & 205 \\
\hline & $\begin{array}{c}\text { 6-Hour } \\
\text { Antecedent }\end{array}$ & 0.048 & 0.039 & 0.580 & 173 & 0.034 & 0.024 & 0.773 & 158 \\
\hline \multirow{3}{*}{$\begin{array}{l}\text { Reynolds } \\
\text { Creek, ID }\end{array}$} & None & 0.041 & -0.035 & 0.172 & 74 & 0.044 & -0.039 & 0.045 & 76 \\
\hline & $\begin{array}{c}\text { Active } \\
\text { Rain } \\
\end{array}$ & 0.039 & -0.034 & 0.199 & 70 & 0.044 & -0.039 & 0.080 & 69 \\
\hline & \begin{tabular}{|c|} 
6-Hour \\
Antecedent
\end{tabular} & 0.040 & -0.035 & 0.118 & 59 & 0.042 & -0.037 & 0.107 & 63 \\
\hline
\end{tabular}


Table VI. Comparison of SMOS tau and vegetation water content (derived from NDVI climatology values). Period of analysis is Jan. 2010-Dec. 2010.

\begin{tabular}{|c|c|c|c|c|c|c|c|c|c|c|}
\hline \multirow{2}{*}{ Watershed } & \multirow{2}{*}{ Overpass } & \multicolumn{3}{|c|}{ Tau } & \multicolumn{3}{|c|}{$\begin{array}{c}\text { Vegetation Water Content } \\
\left(\mathrm{kg} / \mathrm{m}^{2}\right)\end{array}$} & \multicolumn{3}{|c|}{ MODIS Estimated Tau } \\
\hline & & Average & Minimum & Maximum & Average & Minimum & Maximum & Average & Minimum & Maximum \\
\hline \multirow{2}{*}{$\begin{array}{l}\text { Walnut } \\
\text { Gulch, AZ }\end{array}$} & Ascending & 0.18 & 0.01 & 0.42 & \multirow{2}{*}{0.59} & \multirow{2}{*}{0.48} & \multirow{2}{*}{0.90} & \multirow{2}{*}{0.059} & \multirow{2}{*}{0.048} & \multirow{2}{*}{0.090} \\
\hline & Descending & 0.21 & 0.03 & 0.43 & & & & & & \\
\hline \multirow{2}{*}{$\begin{array}{c}\text { Little } \\
\text { Washita, OK }\end{array}$} & Ascending & 0.24 & 0.06 & 0.43 & \multirow{2}{*}{1.17} & \multirow{2}{*}{0.79} & \multirow{2}{*}{1.48} & \multirow{2}{*}{0.117} & \multirow{2}{*}{0.079} & \multirow{2}{*}{0.148} \\
\hline & Descending & 0.19 & 0.01 & 0.37 & & & & & & \\
\hline \multirow{2}{*}{$\begin{array}{l}\text { Little River, } \\
\text { GA }\end{array}$} & Ascending & 0.32 & 0.07 & 0.58 & \multirow{2}{*}{1.49} & \multirow{2}{*}{1.21} & \multirow{2}{*}{1.88} & \multirow{2}{*}{0.149} & \multirow{2}{*}{0.121} & \multirow{2}{*}{0.188} \\
\hline & Descending & 0.30 & 0.07 & 0.57 & & & & & & \\
\hline $\begin{array}{l}\text { Reynolds } \\
\text { Creek, ID }\end{array}$ & Ascending & 0.22 & 0.08 & 0.43 & 0.77 & 0.69 & 0.94 & 0.077 & 0.069 & 0.094 \\
\hline
\end{tabular}




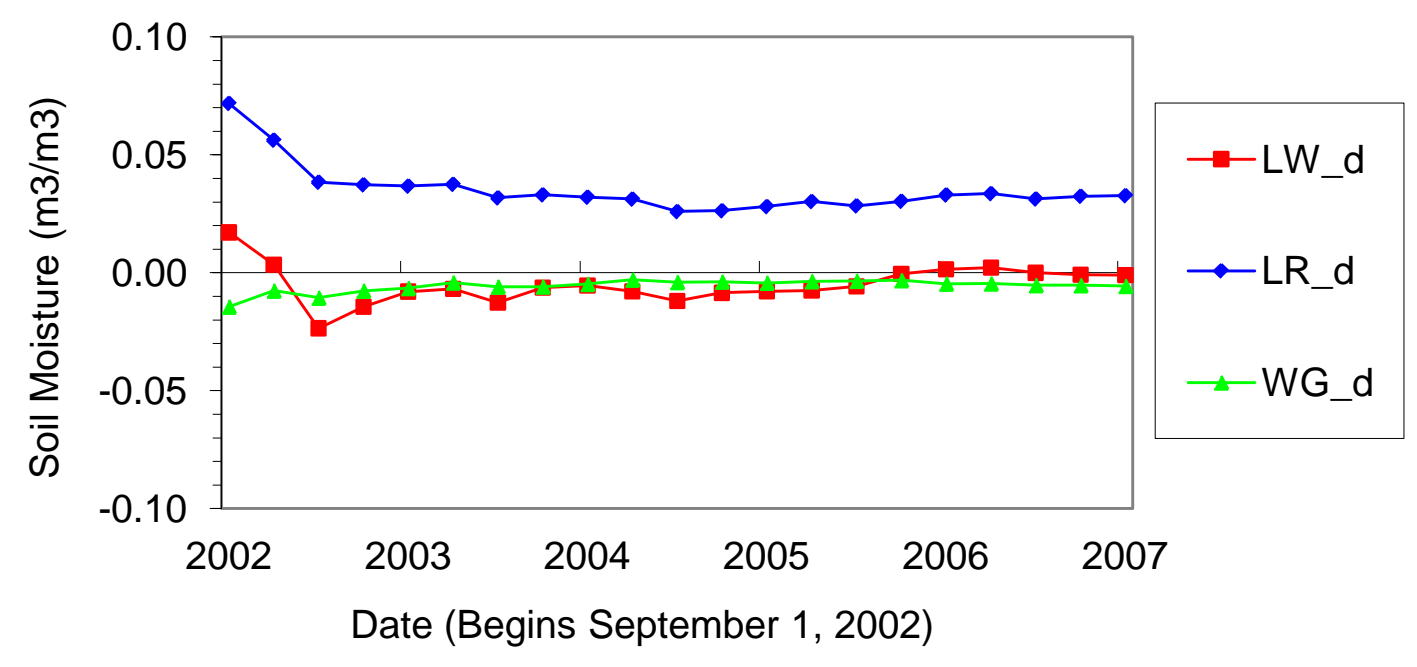

a)

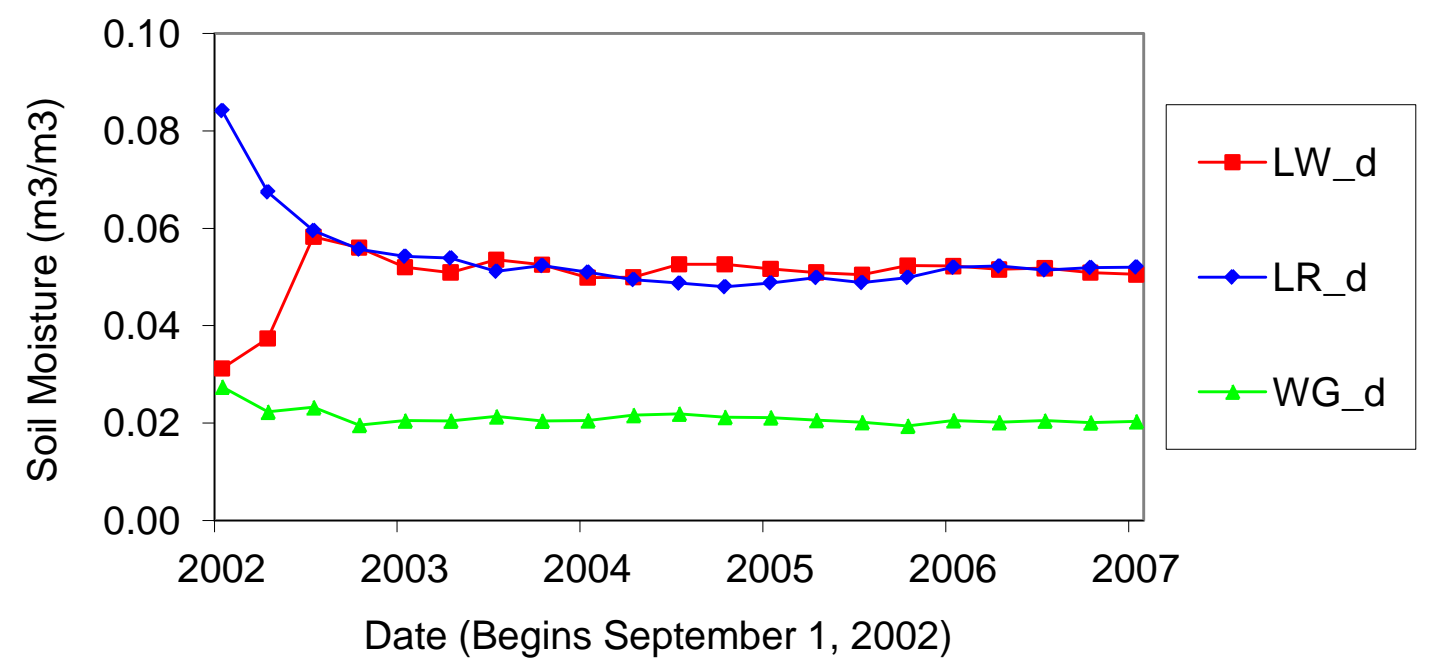

b)

Figure 1. AMSR-E validation with increasing period of record for descending (d) passes; a) bias and b) RMSE. Legend refers to Little Washita (LW), Little River (LR), and Walnut Gulch (WG). 


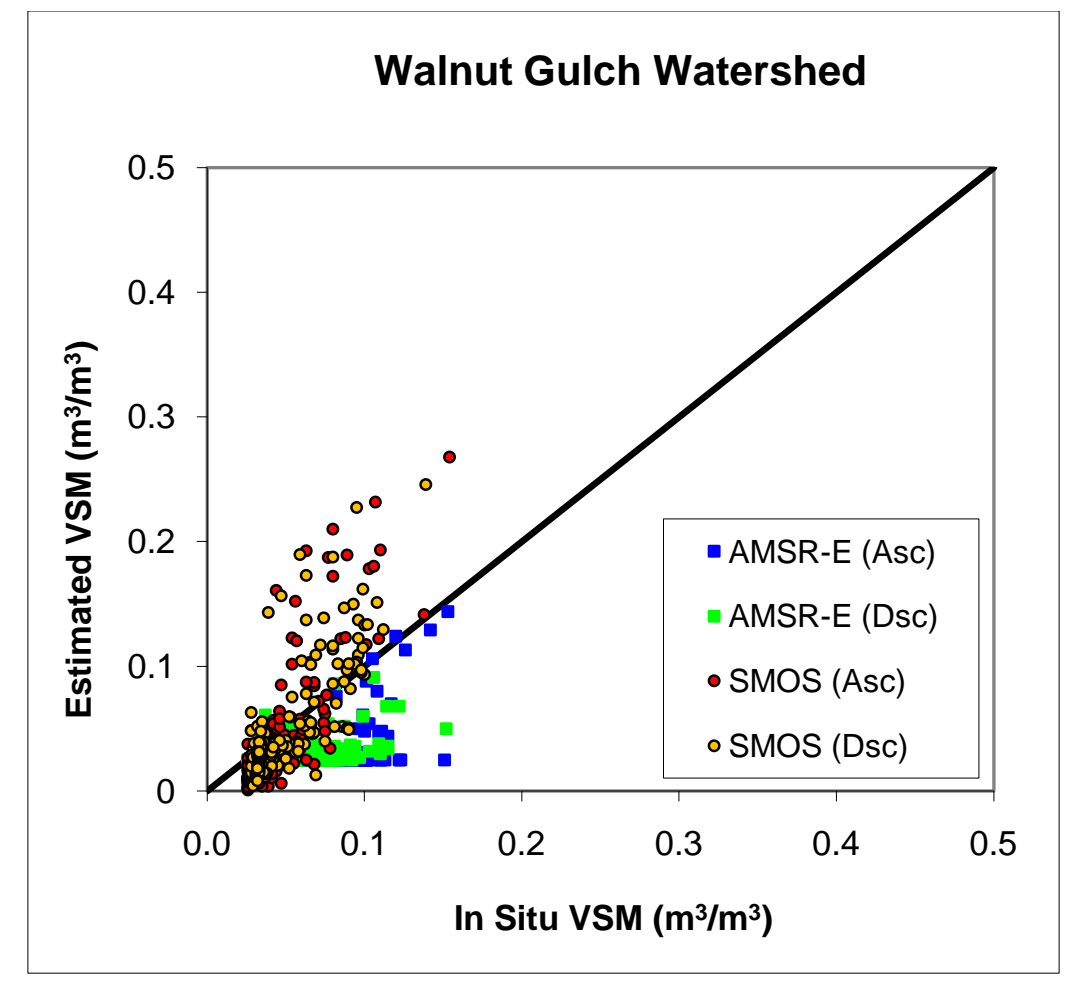

a)

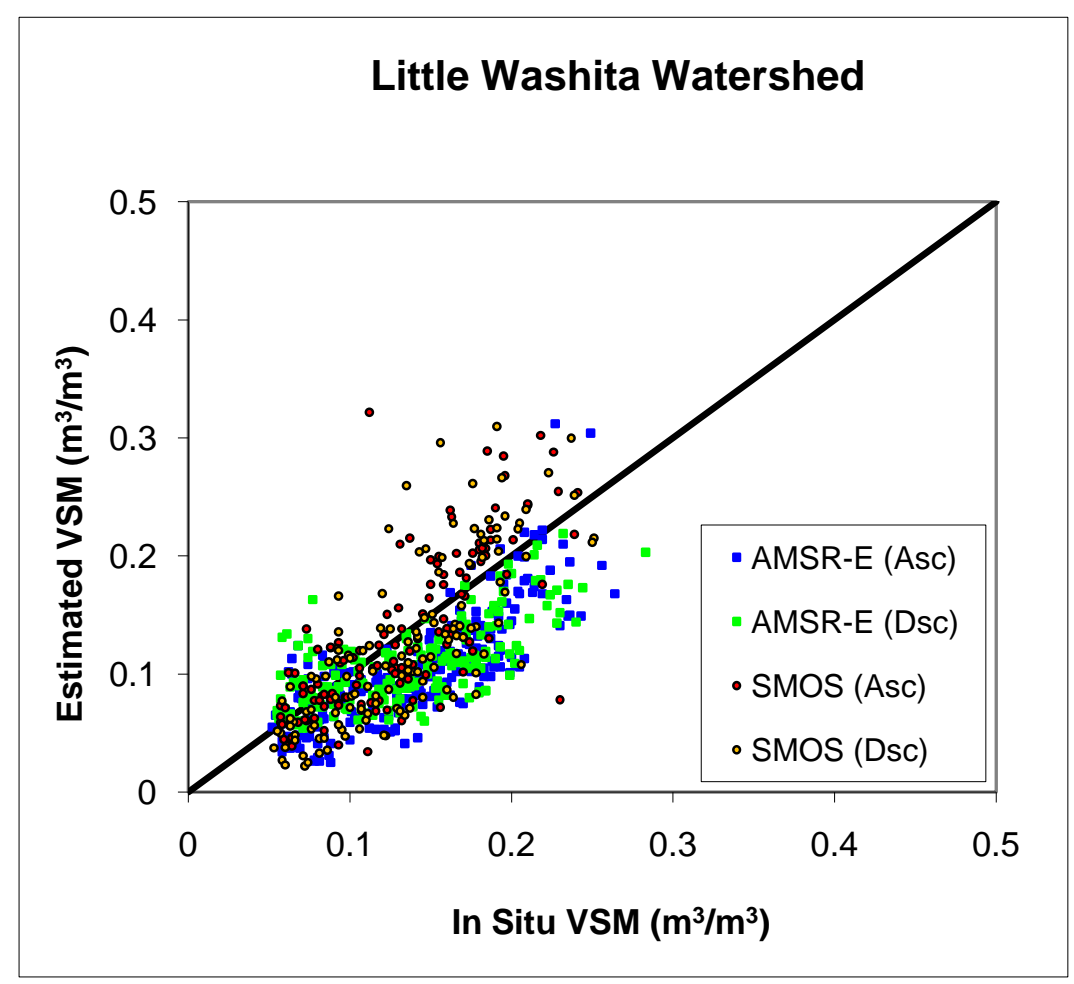

b) 


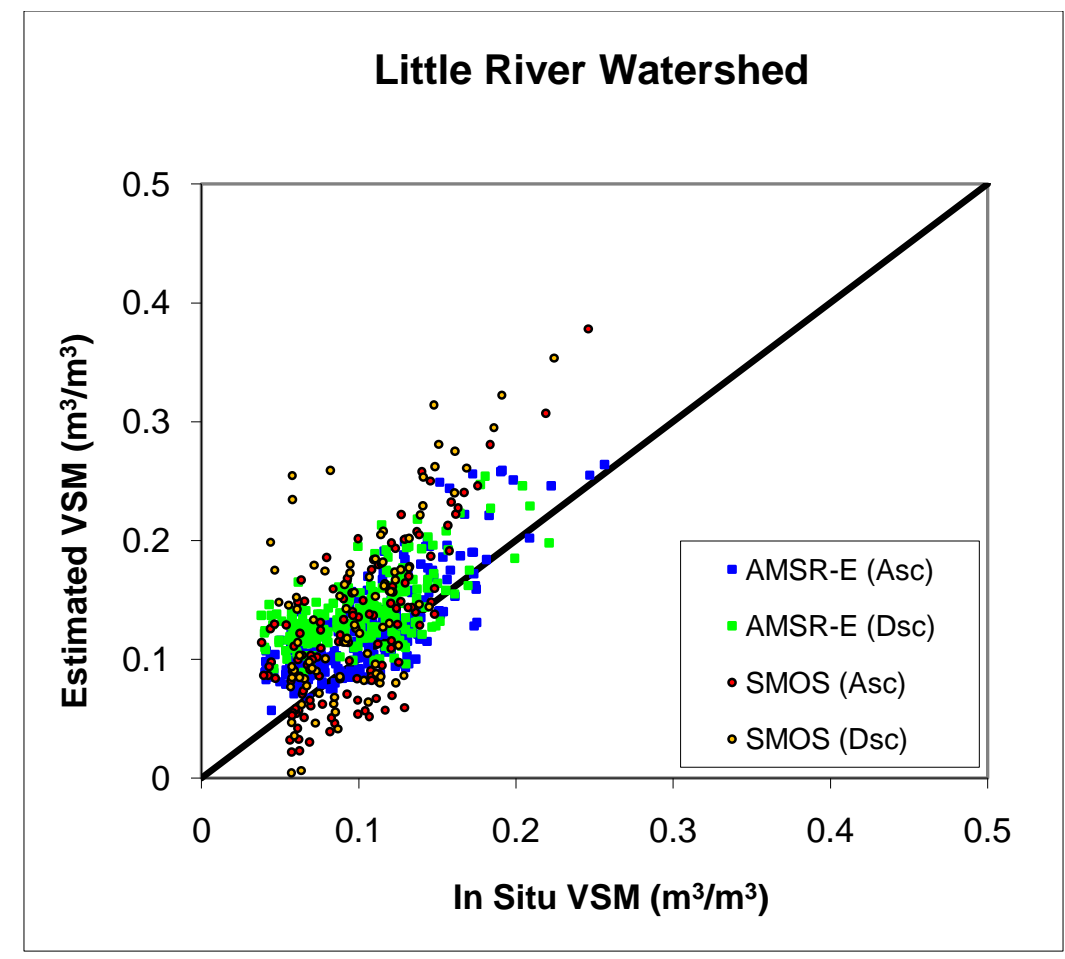

c)

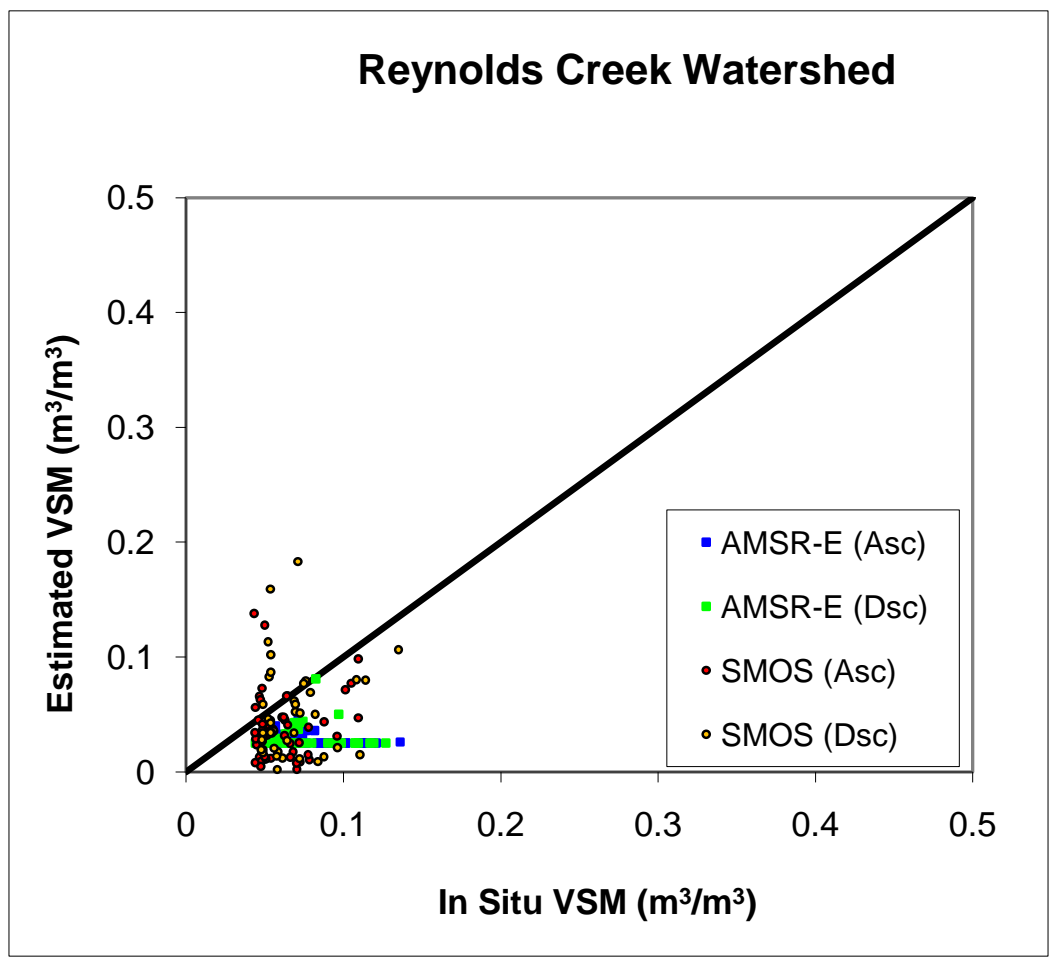

d) 
Figure 2. In situ volumetric soil moisture (VSM) versus satellite retrieved soil moisture; a) WG, b) LW, c) LR, and d) RC. In situ VSM is the network average for the nearest hourly time step to the satellite overpass. 


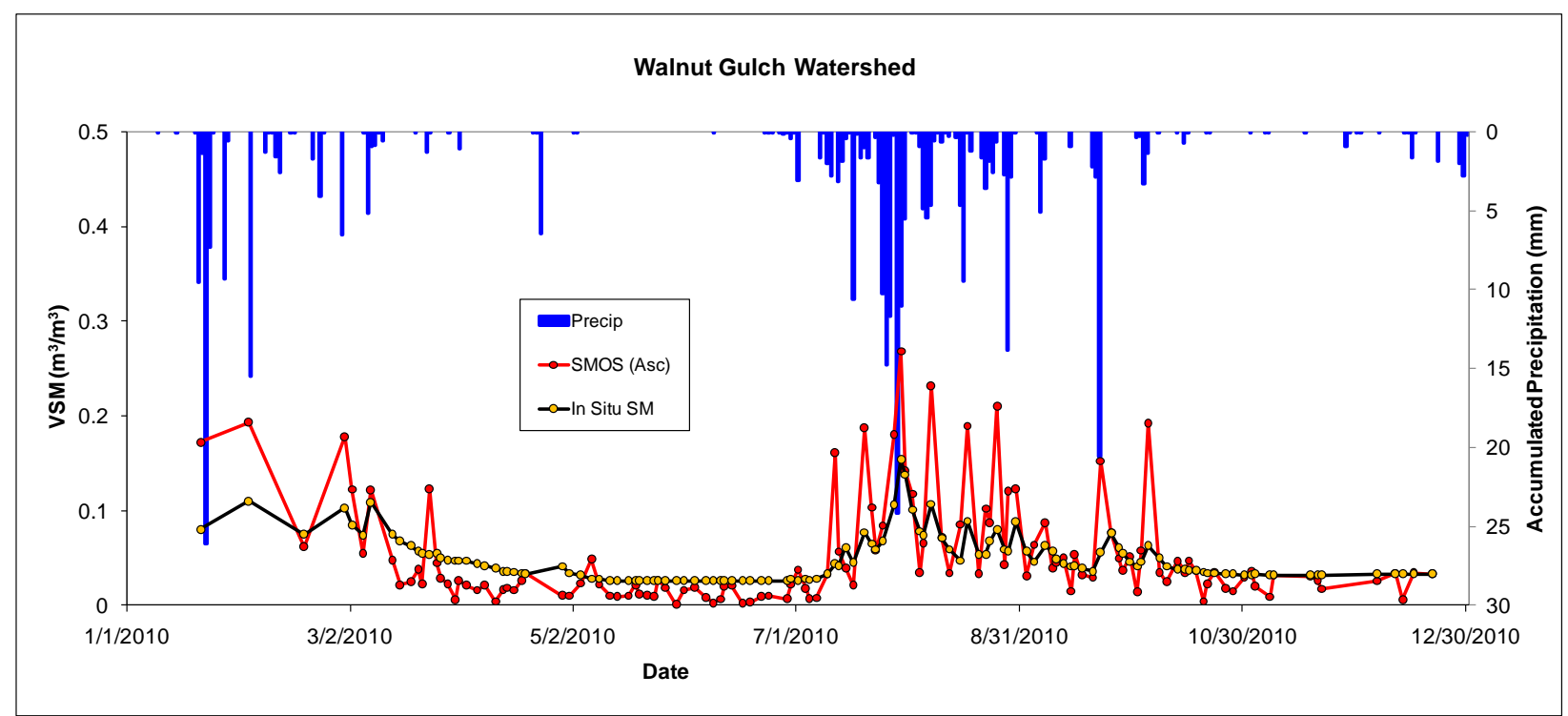

a)

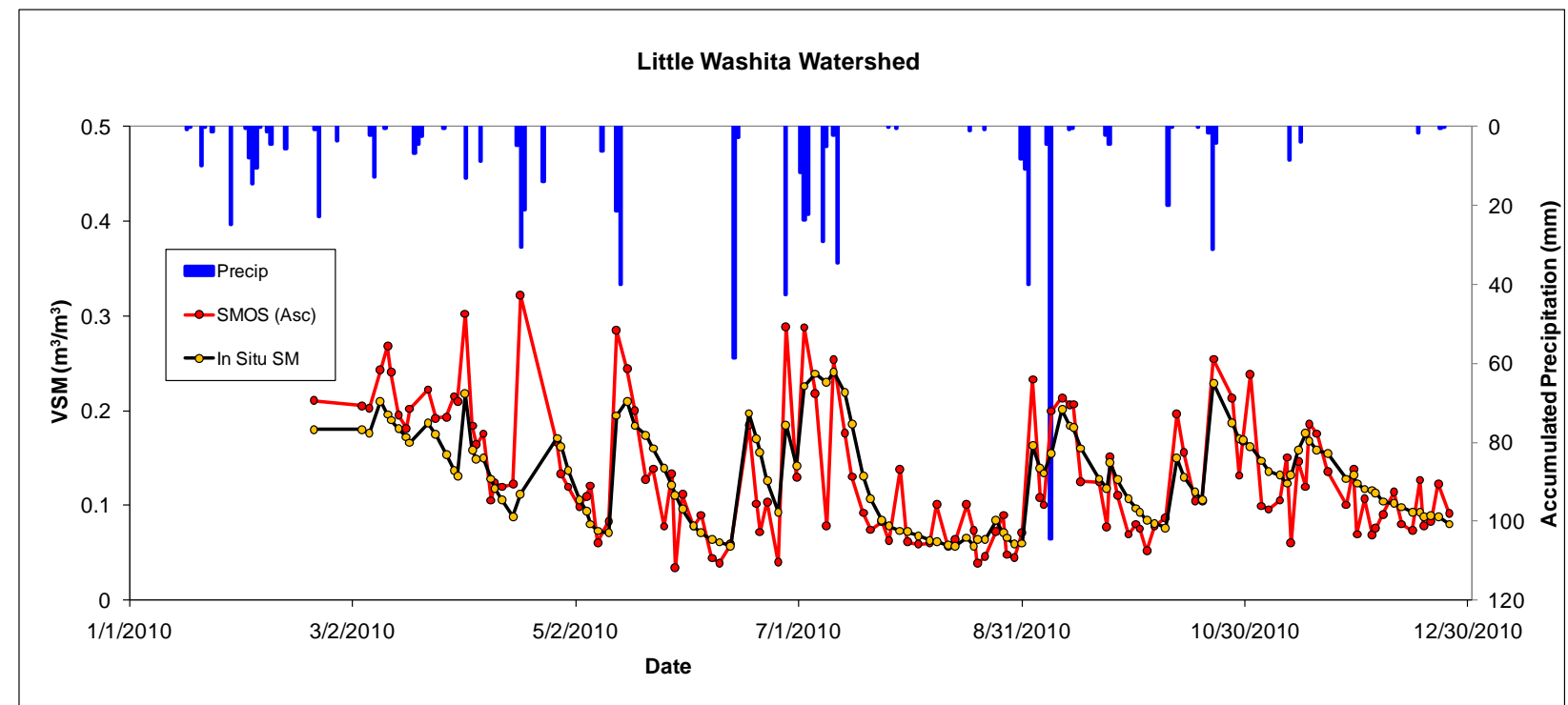

b) 


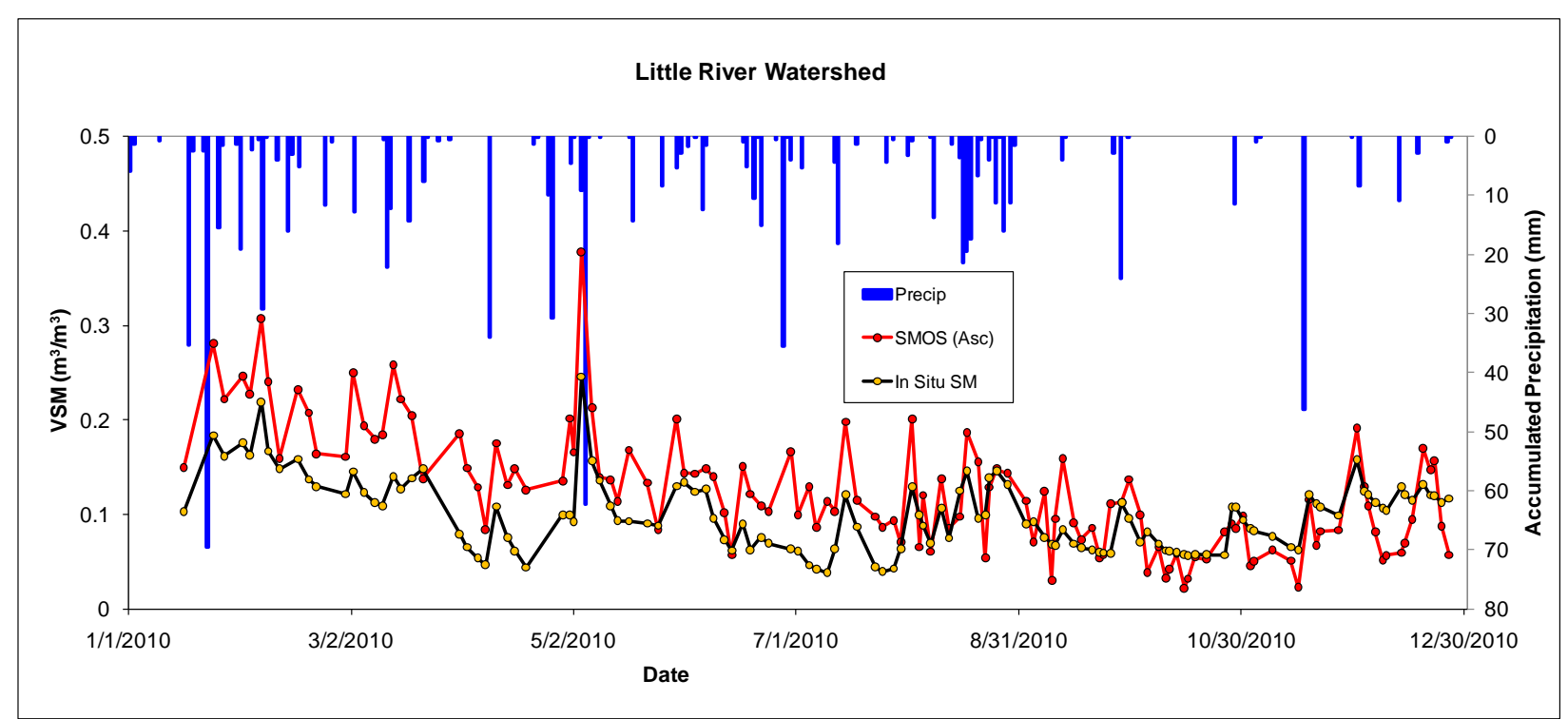

c)

Reynolds Creek Watershed

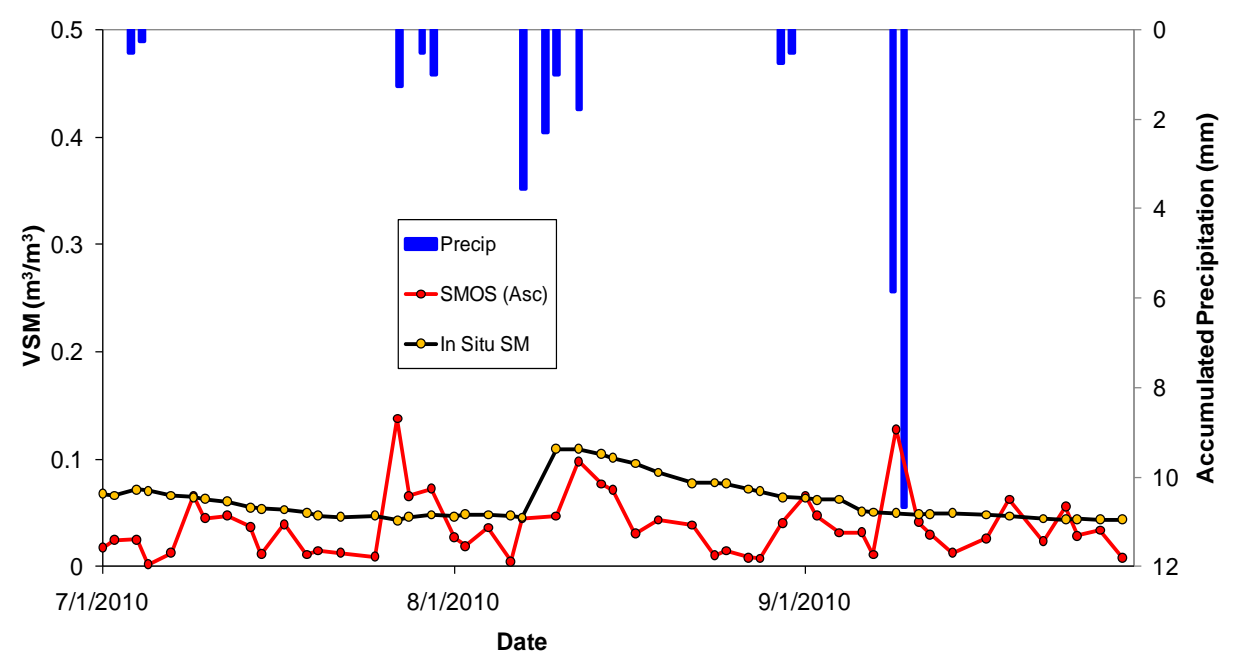

d)

Figure 3. Temporal plots of in situ VSM and SMOS soil moisture and antecedent precipitation (ascending only) a) WG, b) LW, c) LR, and d) RC. 


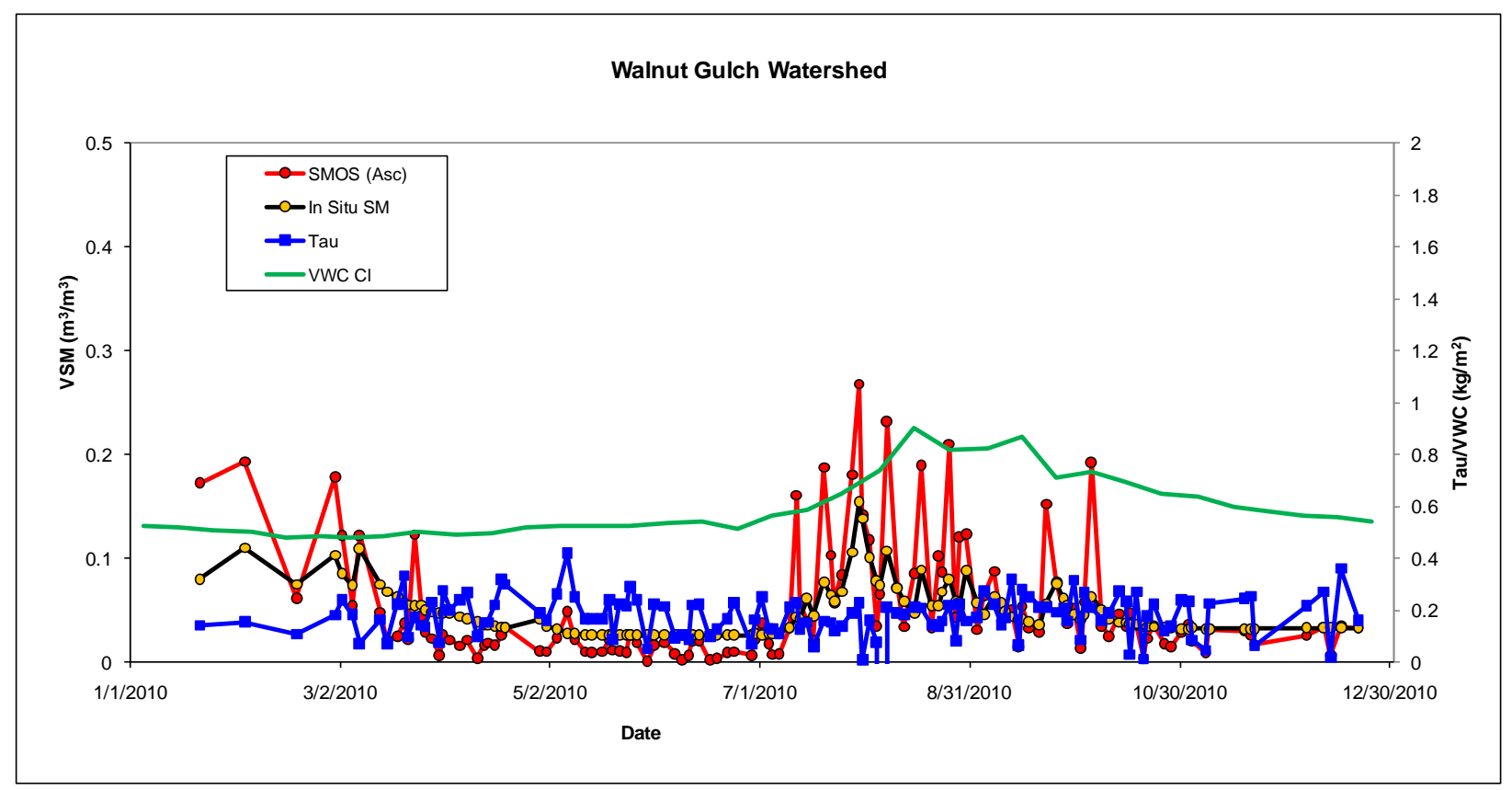

a)

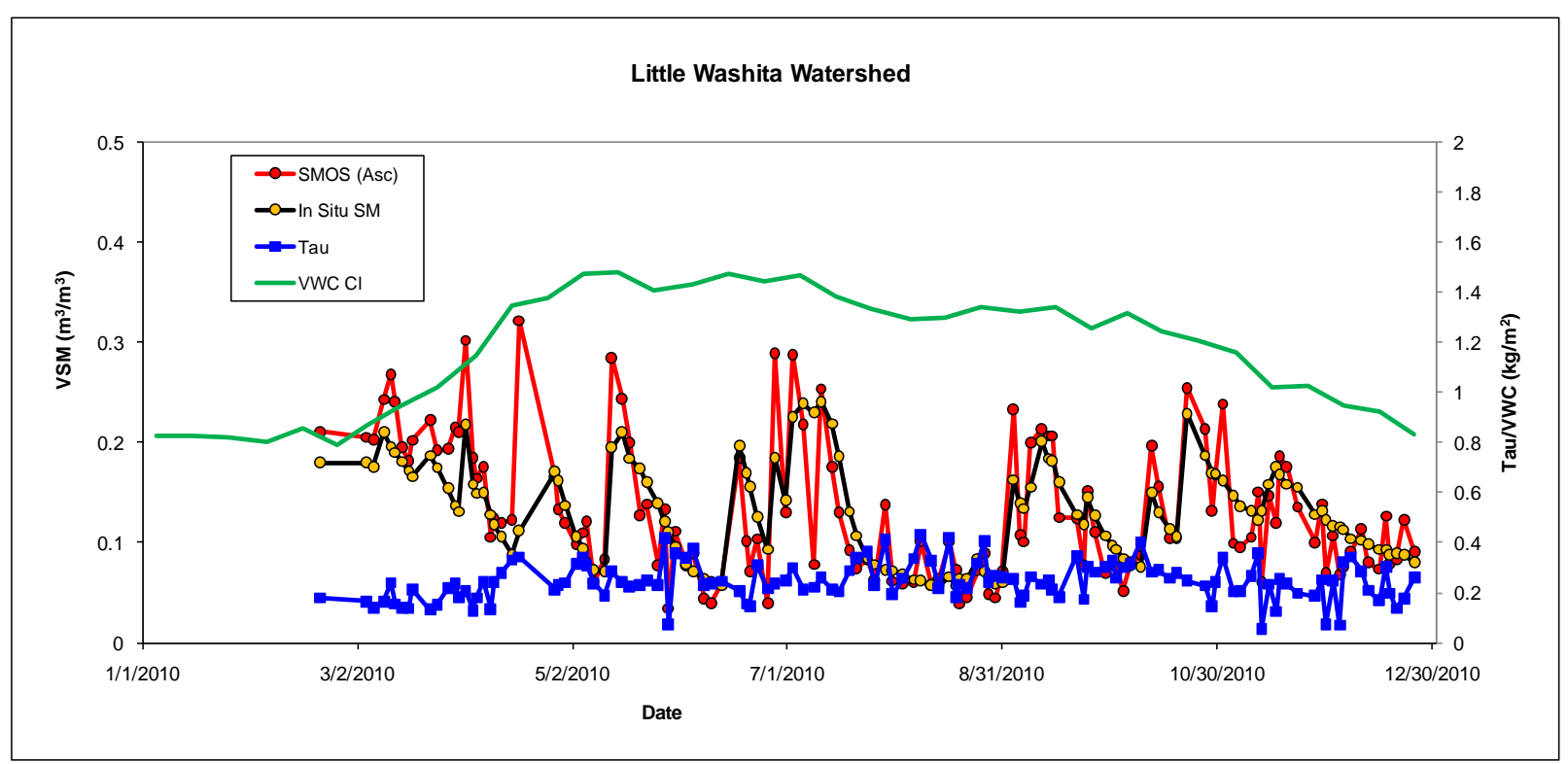

b) 


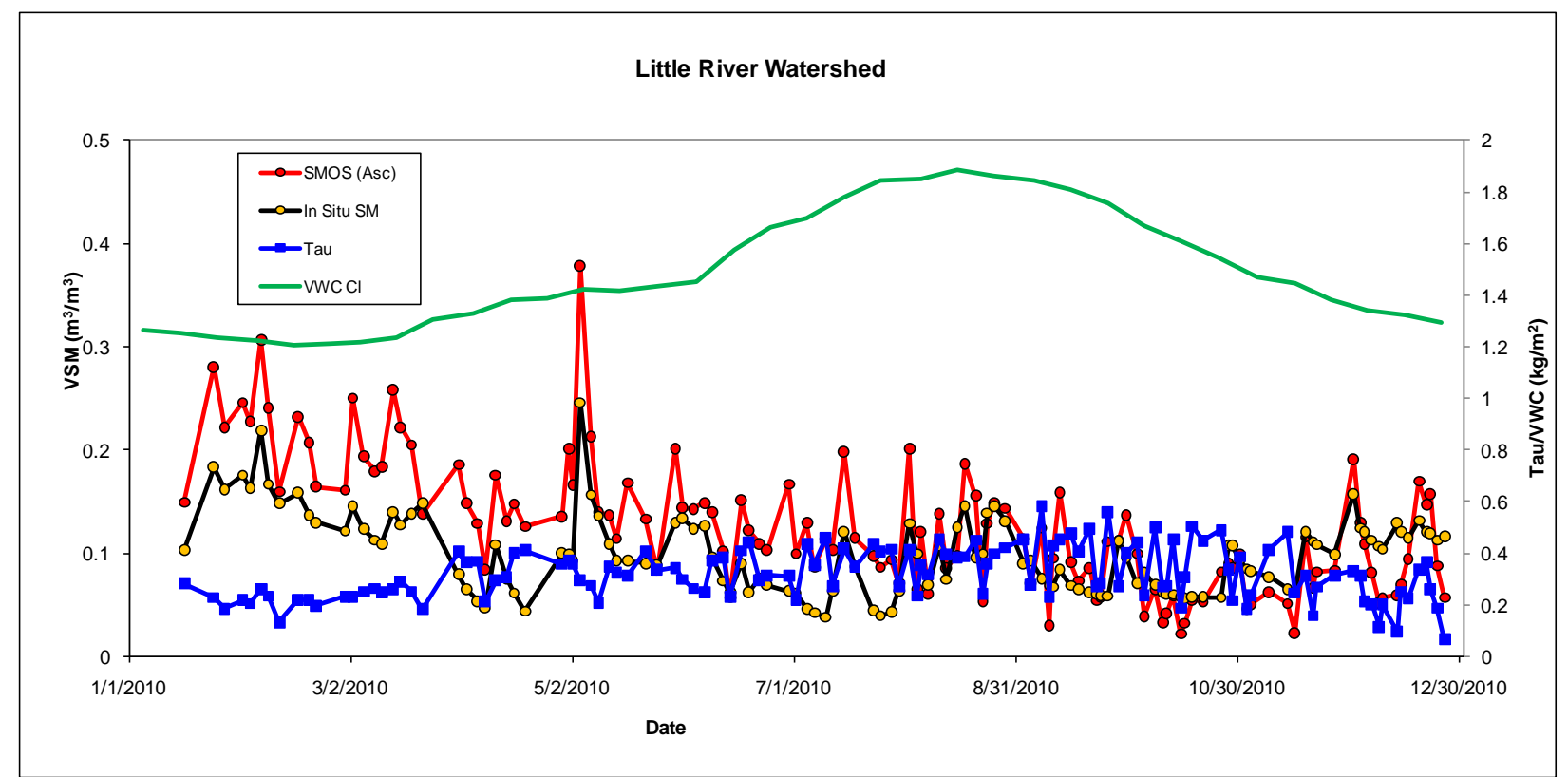

c)

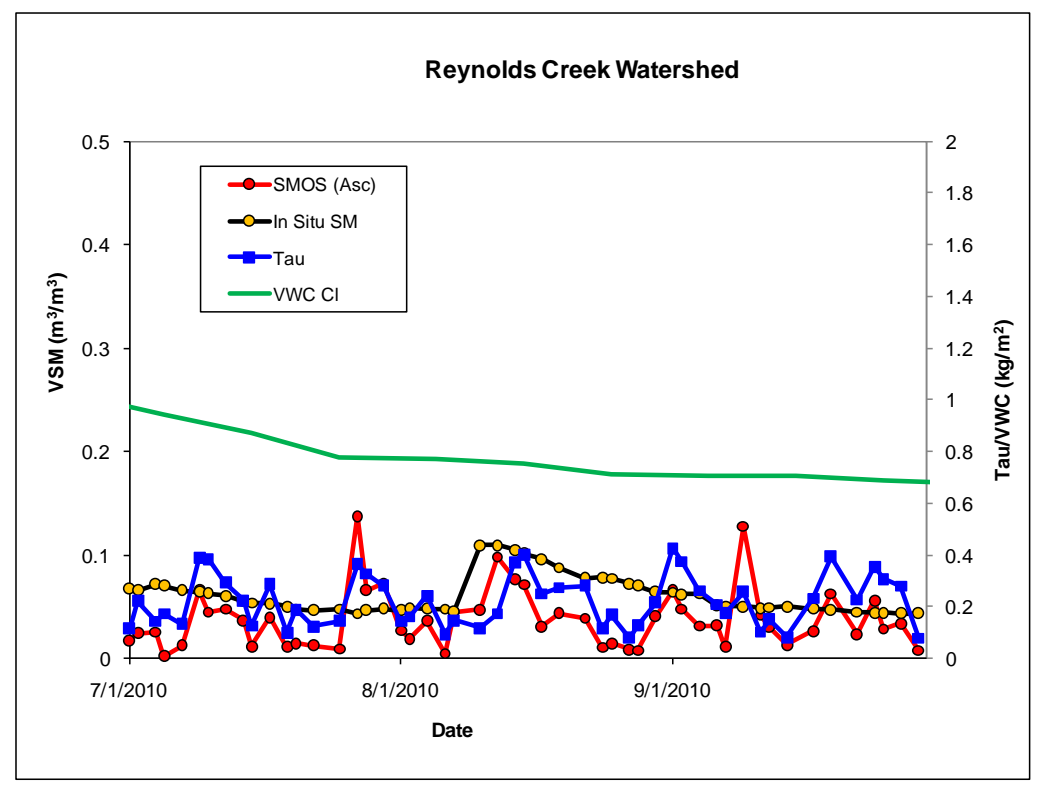

d)

Figure 4. Temporal plots of tau, vegetation water content, and soil moisture (ascending only); a) WG, b) LW, c) LR, and d) RC. In situ VSM is the network average for the nearest hourly time step to the satellite overpass. 